\title{
Cues guiding uloborid construction behavior support orb web monophyly
}

\author{
William G. Eberhard ${ }^{1,2}$ and Gilbert Barrantes ${ }^{2}:{ }^{1}$ Smithsonian Tropical Research Institute; ${ }^{2}$ Escuela de Biología, \\ Universidad de Costa Rica, Ciudad Universitaria, Costa Rica. E-mail: william.eberhard@gmail.com
}

\begin{abstract}
Behavior can provide useful traits for testing phylogenetic hypotheses, and some details of orb web construction behavior have been especially useful in characterizing higher-level groups in spiders. The cues used to guide construction behavior and behavioral responses to these cues hold similar promise, but have never been used in phylogenetic studies. Here we use several techniques to test the hypothesis that orb webs in the two major branches of orb-weaving araneomorph spiders (Araneoidea and Deinopoidea) are monophyletic, using both the cues that guide orb construction and the spiders' responses to these cues. If orb webs evolved only once, the expectation is that these traits should be similar in members of both evolutionary lines. This prediction was supported: species in the two groups use several of the same cues, and respond to them in similar ways. These cues include two identical reference stimuli for positioning sticky spiral lines; supplies of silk available in their glands that affect the positioning of sticky spiral loops; and at least one stimulus related to the size of the available space for the orb, which is used to trigger similar modifications of seven independent orb design traits. Neither group used tension-related cues to guide sticky spiral placement. These comparisons reinforce previous conclusions supporting orb web monophyly that were derived from morphological, molecular, and behavioral traits.
\end{abstract}

Keywords: Behavioral traits, phylogeny, orb web construction

The use of behavioral traits as taxonomic characters has a tangled history. Behavior is often highly variable and context-dependent, and it has been argued that its variability and putative difficulties in determining homologies make it an unreliable indicator of relationships (Atz 1970; Ryan 1996). Several reviews indicate, however, that it is on average neither more nor less reliable than morphology (Roe \& Simpson 1958; Wenzel 1992; deQuiroz \& Wimberger 1993; Kuntner et al. 2008). The growing ability to collect video recordings and make them available in publications (e.g., Puniamoorthy et al. 2008) promises to promote more extensive use of behavior in systematic studies.

In spiders some behavioral traits are taxonomically informative, while others are less useful. On the one hand, some details of orb web construction constitute the least homoplasious group of traits yet found for deciphering the relationships among families and superfamilies of orb weavers (Kuntner et al. 2008; Lopardo et al. 2010). In contrast, the variation in non-orb webs in the family Theridiidae showed such a poor fit with a well-supported tree, which had been established previously on the basis of largely concordant morphological and molecular traits, that their analysis was described as "chaos from order" (Eberhard et al. 2008).

To our knowledge, previous taxonomic analyses of behavior have generally or exclusively utilized actions or behavior patterns and their results (e.g., web architecture). The present paper breaks new ground by concentrating not on actions per se, but rather on the stimuli that are used to direct and guide actions, and on the rules that determine the responses that animals make to these stimuli. This focus opens an additional, possibly independent dimension for exploration. It is feasible for a given behavioral activity to persist through evolutionary time but for the stimuli that are used to elicit or guide it to change. Thus, for instance, bembecine wasps all use their mandibles and forelegs to dig nesting holes in the ground; but the cues that elicit digging behavior presumably vary in groups that nest in different types of substrate (hard packed soil, sand, etc.) (Evans 1966). And, vice versa, the cues that elicit and guide an animal may remain unchanged even when the behavior itself changes. For instance, web-building spiders have continued to use the vibrations generated by their prey to guide their attack behavior, even while attack behavior has evolved from direct bites to wrapping with dry aciniform silk, and then to wrapping with viscid, aggregate gland silk (Barrantes \& Eberhard 2007).

The possibility that behavioral actions and cues could evolve independently is particularly strong in orb weaving spiders. This is because the geometric regularity of an orb means that there are often several different types of potential cues, such as angles between lines, distances between lines, and vibrations or tensions that could be used to guide any particular decision during construction. For example, some species use multiple, largely redundant cues to guide decisions regarding sticky spiral placement (Eberhard \& Hesselberg 2012). As a result, the cues and behavior involved in orb web construction offer a particularly attractive opportunity to use behavioral cues to examine an old, classic controversy concerning the monophyletic or polyphyletic origin of orb webs. In this paper, we provide new data on the cues and responses in a species in one of the two major evolutionary lineage of orb weavers (Deinopoidea), and compare them with published data from the other, better-studied major orbweaver lineage (the seven orb-weaving families of Araneoidea) to test the hypothesis that orb webs in these two lineages are monophyletic.

Taxonomic background.-There is a long history of controversy over whether orb webs evolved one or more times in the deinopoid and araneoid lineages. Strong similarities between the two groups in their basic orb designs, in the general stages of building behavior, and in the order of the stages were documented long ago, arguing for a single, monophyletic origin (Wiehle 1931). The major steps in the process of orb construction, and the order in which they are executed are uniform in all of the more than 100 species of orb weavers (both deinopoids and araneoids) that have now been observed building their webs: frame lines and radii are built 
first, then more radii and hub lines; then more hub lines and the temporary spiral are added, working from the hub outward; and finally the sticky spiral is built from the edge of the web inward (summaries in Eberhard 1982, 1990; Kuntner et al. 2008). Observations of alternative construction stages and ordering of operations in other, non-orb weaving species (e.g., construction of the "rectangular orbs" of Synotaxus spp. Simon 1895) (Eberhard 1977, 1995) has shown that this consistency in orb weavers is not simply a result of construction constraints (Coddington 1986).

Nevertheless, dual origins for orb webs were suggested by the great taxonomic importance that was historically placed on the presence or absence of one compound morphological trait: a plate (the cribellum) that is formed from a modified pair of spinnerets, and the comb of bristles on the hind metatarsus (the calamistrum) that is used to comb the silk from this plate (Simon 1892). The likelihood that the orb design is highly adaptive (Witt 1965; Agnarsson et al. 2013), the high degree of flexibility in many aspects of orb design (Herberstein \& Tso 2011), and the recent discovery of orb-like webs in the distantly related group Fecenia (Psechridae) (Bayer 2011; Agnarsson et al. 2013) all make convergence on orb designs seem less unlikely (for histories of these ideas, see Coddington (1986) and Shear (1986)).

Most recent phylogenetic analyses of morphological and behavioral traits (Griswold et al. 1998; Kuntner et al. 2008), as well as molecular traits (Garb et al. 2006; Blackledge et al. 2009; Dimitrov et al. 2012) have supported the single origin hypothesis for orb webs. The degree of support has been controversial, however (Dimitrov et al. 2012), and the question of how ecribellate sticky lines evolved and replaced cribellate sticky lines without any known intermediate orb web forms that lacked sticky lines is still a puzzle (Opell \& Schwend 2009).

Until last year, a general consensus that favored the single origin hypothesis for orb webs seemed to be emerging, based on morphological and behavioral (Griswold et al. 1998; Kuntner et al. 2008) as well as molecular traits (Garb et al. 2006; Blackledge et al. 2009; Dimitrov et al. 2012). In 2014, however, a pair of molecular analyses, which attempted to correct for several potential problems, including artificial inflation of support due to missing data, unequal rates of evolution in different lineages, compositional heterogeneity, and heterotachy (Fernandez et al. 2014, Bond et al. 2014), found support for linking the deinopoids more closely with a large group of about 40 non-orb weaving (and largely webless) families (the "RTA clade"), rather than with araneoids. If this grouping holds up under further tests, it would imply either multiple derivations of orb webs, or a single, even more ancient derivation and a subsequent loss of orbs in the ancestor of the RTA clade (the preferred hypothesis of Bond et al. 2014). In light of these uncertainties, further tests of the monophyly hypothesis based on additional traits are of interest.

Behavioral background.-During orb web construction spiders guide their behavior by sensing and responding to several different cues (Hingston 1920; Eberhard 1972, 1988a; Vollrath 1986, 1987, 1992; Eberhard \& Hesselberg 2012). The cues that are used by araneoids to guide sticky spiral placement can be divided into two groups: "reference stimuli" that are perceived anew each time a spider arrives at the next radius (e.g., cues from the positions of the radius and the lines already attached to it); and "general settings" stimuli that are not associated with particular sites in the web (e.g., body size and weight of the spider, nutritional status, silk reserves, and the spider's general position in the web with respect to vertical, and to the hub vs. the edge). One reference stimulus that guides sticky spiral placement in araneoids was demonstrated nearly 100 years ago by the pioneer naturalist, R. W. G. Hingston. When he removed a segment of the inner loop of sticky spiral while the araneid spider Neoscona nautica (L. Koch 1875) was laying sticky spiral line (Fig. 1a: a "Hingston experiment" hereafter), Hingston found that the site of the inner loop of sticky spiral is used as a reference point (the "inner loop site" cue hereafter) to guide the placement of the following loop of sticky line: the next sticky spiral attachment was displaced outward on the radius to the site where he had experimentally broken the inner loop, while its placement was not altered on the preceding or the subsequent radius where the previous loop remained intact (Fig. 1a) (Hingston 1920).

Subsequent Hingston experiments with other species in the araneoid families Araneidae, Nephilidae and Tetragnathidae showed that they also use the inner loop site cue (Peters 1954; Eberhard \& Hesselberg 2012). Additional, finer analyses of the results of Hingston experiments, in combination with experimental removal of segments of the temporary spiral and correlations in finished webs, showed that spiders also use a second reference cue, the distance from the outer loop of temporary spiral (the "temporary spiral distance" cue) to guide sticky spiral spacing in both an araneid and a tetragnathid (Eberhard 2011; Eberhard \& Hesselberg 2012).

The experimental demonstration that the site of the inner loop of sticky spiral provides important reference cues during sticky spiral construction complements the behavioral observation concerning how many orb weavers move their legs during sticky spiral construction. Legs I and II are moved in ways that appear designed to locate the inner loop just before each sticky spiral attachment is made (the "inner loop localization behavior" of Eberhard 1982; Scharff \& Coddington 1997; Kuntner et al. 2008). (It should be kept in mind that an orb weaver is effectively blind with respect to the lines in its web; tapping behavior with its legs is equivalent to a blind man tapping with his cane). Uloborid sticky spiral construction behavior includes similar inner loop localization behavior with its legs I (Eberhard 1972, 1982), suggesting that these spiders also use cues from the inner loop to guide sticky spiral placement; but Hingston experiments have never been performed with any uloborid.

The probable effects of one general settings cue - the amount of reserves of sticky silk in the spider's silk glands-were established by experimentally interrupting araneid and tetragnathid spiders after they had laid the non-sticky lines but before they laid the sticky lines in a new orb, removing the web, and then observing the design of the replacement webs that they built a few hours later (Eberhard 1988b). Webs built after this experimental treatment were larger in overall web size and had smaller distances between loops of sticky spiral than control webs that were built after removal of newly built complete orbs (thus allowing the spider to decrease its reserves of sticky silk).

Another recent experimental technique allowed comparative study of several additional responses in several araneoid 


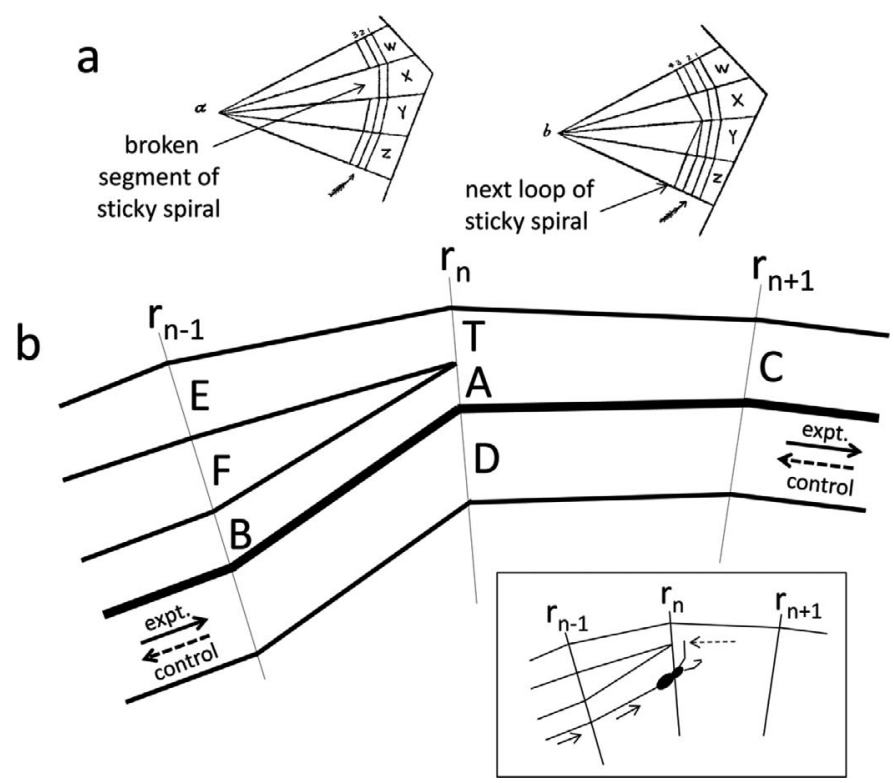

Figure 1.-a) Hingston's drawings illustrate that when he experimentally removed a segment of sticky spiral during sticky spiral construction (left), the araneid Neoscona nautica displaced the attachment of the next loop (loop 4 in b) outward on the radius (between $\mathrm{X}$ and $\mathrm{Y}$ ) (right) (feathered arrow indicates the direction the spider moved) (from Hingston 1920). Judging by more recent observations, the outward deflection of the next loop was probably exaggerated in this drawing (see Eberhard \& Hesselberg 2012). b) Schematic representation of distances associated with an encounter with a turn back that resulted in a spontaneous "Hingston experiment" in a $Z$. geniculata web. The thinnest lines are non-sticky radii, and thicker lines are sticky spiral lines; the thickest is the sticky spiral loop during whose construction a spontaneous "experiment" (or a "control") occurred. When the spider encountered the radius $\left(\mathrm{r}_{\mathrm{n}}\right)$ on which a turn back had occurred while moving one direction ("expt." arrows), her oI failed to contact the inner loop of the turn back (dotted arrow in inset) during inner loop localization behavior, and an "experiment" occurred: the stimuli available to the spider were similar to those in a Hingston experiment in which the inner loop between $r_{n}$ and $r_{n+1}$ had been broken. In contrast, when the spider encountered a turn back while moving in the opposite direction ("control" arrows), leg oI did touch the inner line of the turn back; such encounters thus amounted to "controls". The monophyly hypothesis, that the uloborid uses the same cues in the same ways as araneoids, thus predicts that A would be smaller than B, C, and D in experimental encounters, and that it would be similar to B, C, and D in control encounters. Both predictions were fulfilled.

species. Spiders were induced to build orbs in small containers that severely restricted the spaces in which they could build, and this resulted in changes in several design features of the orbs they built in the araneids Eustala illicita (O. P.Cambridge 1889) and Cyclosa caroli (Hentz 1850), the nephilid Nephila clavipes (Linnaeus 1767), and the tetragnathid Leucauge argyra (Walckenaer 1841) (Hesselberg 2010; Barrantes \& Eberhard 2012). This technique has the disadvantage that the precise cue or cues that are used by the spider to sense the size of the space are not known; but it elicits up to seven apparently independent behavioral responses (Barrantes \& Eberhard 2012). The expectation of the monophyly hypothesis is that the changes in uloborid orbs built in especially small containers will resemble the changes seen in the orbs of araneoids built in similarly restricted spaces.

Aims of this study. - The present study compares data from previous studies of araneoid and uloborid spiders, and new observations of a representative of the deinopoids, the uloborid Zosis geniculata (Olivier 1789). The monophyly hypothesis predicts that both the cues that spiders use and the responses that they give to these cues should be similar in deinopoids and araneoids. The degree of difference between uloborids and araneoids should not be substantially greater than that among the different families of araneoids. Extensive comparisons have not been possible before, because most of the previous experimental studies of the cues guiding orb construction behavior have involved only araneoids.

\section{METHODS}

General conditions.-We collected adult females of the synanthropic uloborid Zosis geniculata in buildings in San Rafael de Escazú (about $1000 \mathrm{~m}$ el.) and near Tárcoles, Costa Rica (about $20 \mathrm{~m}$ el.). We housed them individually in approximately cylindrical plastic containers of variable diameters (see below) whose upper, detachable rims (cut from similar containers) were lined with black paper that allowed spiders to walk easily and attach their lines. The open end at the top of each cylinder was covered with tightly stretched plastic wrapping material, to which spiders almost never attached their lines. After a web was built, we induced the spider to leave the web, removed the upper rim, coated the web on it lightly with talcum powder, and photographed it against a black background. We measured the lengths and areas and counted the web elements listed in Table 1 from digital photographs of webs using the NIH program "Image J" as in the previous study of L. argyra (Barrantes \& Eberhard 2012).

Analyses of orb webs are facilitated by the large number of measurements that can be made on each web, but they are also challenging, because some variables may be correlated with each other only due to the regular geometry of the orb. We confronted this possible problem by measuring and reporting a wide variety of comparisons, but focusing on variables that are most likely to be independent of each other, especially on traits that are determined at different stages of orb construction (see discussion in Barrantes \& Eberhard 2012).

To avoid measuring the same traits twice (Table 1), and to facilitate comparisons with the araneoid Leucauge argyra, we followed the conservative criteria for judging the independence and classification of different variables on the basis of their probable independence that were used by Barrantes \& Eberhard (2012). The overall objective was to emphasize those web traits that resulted from different and thus possibly independent decisions made by the spider during construction and that could evolve independently. For instance, web design changes that were direct physical consequences of our manipulations were not counted: thus the association between reduced total area of the web and confinement in smaller spaces was not counted. Those stimuli and analyses of stimuli that spiders are unlikely to be able to perceive or to perform were also not counted. Thus we did not suppose that the spiders made any direct decisions regarding the number of loops of sticky spiral, as we judged that it was more likely that the number of loops was determined not by counting, but as 
Table 1.- Relationship of total area of the web and 18 other web features, including the relationships between total area and the proportion of three features over the total area (each variable/total area) for webs built by Zosis geniculata spiders in containers with four different diameters, and comparison between slopes (t-test) of the same 18 variables for $Z$. geniculata and Leucauge argyra. $F$-test for the slope $\left(\mathrm{H}_{0}\right.$ : $\left.\mathrm{b}=0\right)$, the slope values (b), standard error (SE) for slopes, and the proportion of the variance of each dependent variable explained by the total area ( $\mathrm{r}^{2}$ ) are included. All variables were $\log 10$-transformed. L indicates the longest radius, and areas are given as the square root of the actual values. Values of the t-test and probabilities are not presented for those features in which the slope did not differ statistically from zero in both $Z$. geniculata and L. argyra.

\begin{tabular}{|c|c|c|c|c|c|c|c|c|c|c|}
\hline \multirow[b]{2}{*}{ Variable } & \multicolumn{6}{|c|}{ Z. geniculata } & \multicolumn{4}{|c|}{ Z. geniculata vs. L. argyra } \\
\hline & $F$ & $\mathrm{df}$ & $\mathrm{b}$ & SE & $r^{2}$ & $P$ & $\mathrm{~b}$ & SE & t-test & $P$ \\
\hline \multicolumn{11}{|l|}{ Total area (independent variable) } \\
\hline Capture area & 2836.0 & $1 / 117$ & 2.29 & 0.043 & 0.96 & $<0.00001$ & 1.39 & 0.029 & 17.23 & $<0.00001$ \\
\hline Free zone area & 270.3 & $1 / 117$ & 1.15 & 0.070 & 0.70 & $<0.00001$ & 0.68 & 0.048 & 5.54 & $<0.00001$ \\
\hline Hub area & 511.6 & $1 / 117$ & 1.12 & 0.049 & 0.81 & $<0.00001$ & 0.23 & 0.025 & 16.01 & $<0.00001$ \\
\hline Number of radii & 472.6 & $1 / 117$ & 1.28 & 0.059 & 0.80 & $<0.00001$ & 0.40 & 0.023 & 13.89 & $<0.00001$ \\
\hline No. sticky spiral loops & 135.6 & $1 / 117$ & 1.77 & 0.147 & 0.54 & $<0.00001$ & 0.89 & 0.044 & 6.24 & $<0.00001$ \\
\hline Sticky spiral space on $\mathrm{L}$ & 26.0 & $1 / 117$ & 0.70 & 0.139 & 0.18 & $<0.00001$ & 0.42 & 0.047 & 1.94 & 0.05297 \\
\hline Consistency st. sp. spaces on $\mathrm{L}$ & 3.1 & $1 / 104$ & -0.07 & 0.040 & 0.03 & 0.0795 & 0.03 & 0.016 & & \\
\hline Dist. from outer loop & 83.4 & $1 / 116$ & 3.49 & 0.382 & 0.42 & $<0.00001$ & 1.04 & 0.123 & 6.12 & $<0.00001$ \\
\hline Dist. longest radius & 910.2 & $1 / 115$ & 2.85 & 0.094 & 0.89 & $<0.00001$ & 0.91 & 0.029 & 19.59 & $<0.00001$ \\
\hline Dist. shortest radius & 526.7 & $1 / 115$ & 2.68 & 0.117 & 0.82 & $<0.00001$ & 1.05 & 0.045 & 12.98 & $<0.00001$ \\
\hline Web symmetry & 0.25 & $1 / 115$ & 0.02 & 0.036 & 0.002 & 0.618 & 0.44 & 0.065 & 5.68 & $<0.00001$ \\
\hline Prop. radii attached to substrate & 37.7 & $1 / 113$ & -0.27 & 0.044 & 0.25 & $<0.00001$ & -1.03 & 0.061 & 9.98 & $<0.00001$ \\
\hline Prop. frame w. single radius & 17.2 & $1 / 113$ & -0.21 & 0.050 & 0.13 & 0.00007 & -0.46 & 0.068 & 2.28 & 0.02355 \\
\hline Mean radii/frame & 120.9 & $1 / 113$ & 0.82 & 0.074 & 0.52 & $<0.00001$ & 0.43 & 0.028 & 4.93 & $<0.00001$ \\
\hline Number of frame lines & 39.08 & $1 / 116$ & 0.73 & 0.117 & 0.25 & $<0.00001$ & 0.41 & 0.077 & 2.31 & 0.02212 \\
\hline Prop. capture area/total area & 1155.0 & $1 / 117$ & 0.60 & 0.018 & 0.91 & $<0.00001$ & 0.03 & 0.028 & 17.11 & $<0.00001$ \\
\hline Prop. free zone area/total area & 61.3 & $1 / 117$ & 0.22 & 0.028 & 0.34 & $<0.00001$ & 0.03 & 0.028 & 4.88 & $<0.00001$ \\
\hline Prop. hub area/total area & 149.6 & $1 / 117$ & 0.24 & 0.020 & 0.56 & $<0.00001$ & -0.19 & 0.014 & 17.62 & $<0.00001$ \\
\hline
\end{tabular}

a result of a combination of decisions including how close to the end of the radius to attach the first loop, how far apart subsequent loops were attached, and where sticky spiral construction was terminated. We also took into account the physical feasibility of independence among variables. For instance, it is not physically possible for the total number of radii to be independent of the mean angle between them, so we only measured the number of radii (as an indicator of the angle).

Finally, we considered those variables that were directly affected by decisions that were made at different times during construction, and that are influenced by different cues, as likely to be biologically independent. It is important to note that biological independence is not necessarily the same as statistical independence. For instance, the two variables radius length and the distance from the end of the radius at which the first loop of sticky spiral is attached are correlated statistically (Barrantes \& Eberhard 2012). But radius length is determined much earlier in orb construction than is the placement of the first loop of sticky spiral. Sticky spiral placement is influenced by the site of the outer loop of temporary spiral (Eberhard 1972, 2012), a line that is not even present when radii are being constructed. Thus despite their statistical correlation, we considered these two aspects of design to result from different decisions.

Measurements of spaces between loops of sticky spiral on the longest radius and the radius opposite it differed slightly from those described by Barrantes \& Eberhard (2012) for L. argyra. As in other uloborids (Eberhard 1972; Lubin 1986), $Z$. geniculata does not attach the sticky spiral to each radius it encounters. When a loop of sticky spiral was not attached to a particular radius (determined by lack of an inflection in the sticky line, and by lack of reduction in the diameter of the line associated with the attachment - see Fig. 2b), we measured the inter-loop distance where that loop was attached to the nearest radius. In a few cases, the spacing was uncertain because sticky loops were broken or adhered to each other; in these cases we substituted a measurement of the inter-loop distance on an adjacent radius. We also measured the distance between the outermost loop of sticky spiral and the outer end of the radius (its attachment to a frame line or the wall of the container) for the longest radius and the radius opposite it.

In the behavioral descriptions we use the terms "inner" and "outer" with reference to the hub of the orb; thus the "outer" leg I (leg oI) is farther from the hub than leg iI as the spider circles the web. Similarly, we use the expressions "beyond" or "far side of" with reference to the direction the spider was moving, so a line "beyond" the radius a spider encountered while the circling the web was on the far side of that radius. To improve the clarity of descriptions, we refer to the spiders as "she" rather than "it" (in point of fact, all the spiders in our study were mature females).

Measurements of spaces between sticky spiral lines were standardized to control for differences in spider size, recent feeding history, and the general area of the web by standardizing data: each measurement was divided by either the median space on that radius, or by the spaces just preceding or following an experimental space. It is likely that a spider's responses to cues at different sites in her web were largely independent of each other, but to account for the possible effects of including multiple measurements from the same web and using different webs of the same spider, we analyzed the data with general linear mixed models (GLMM). 


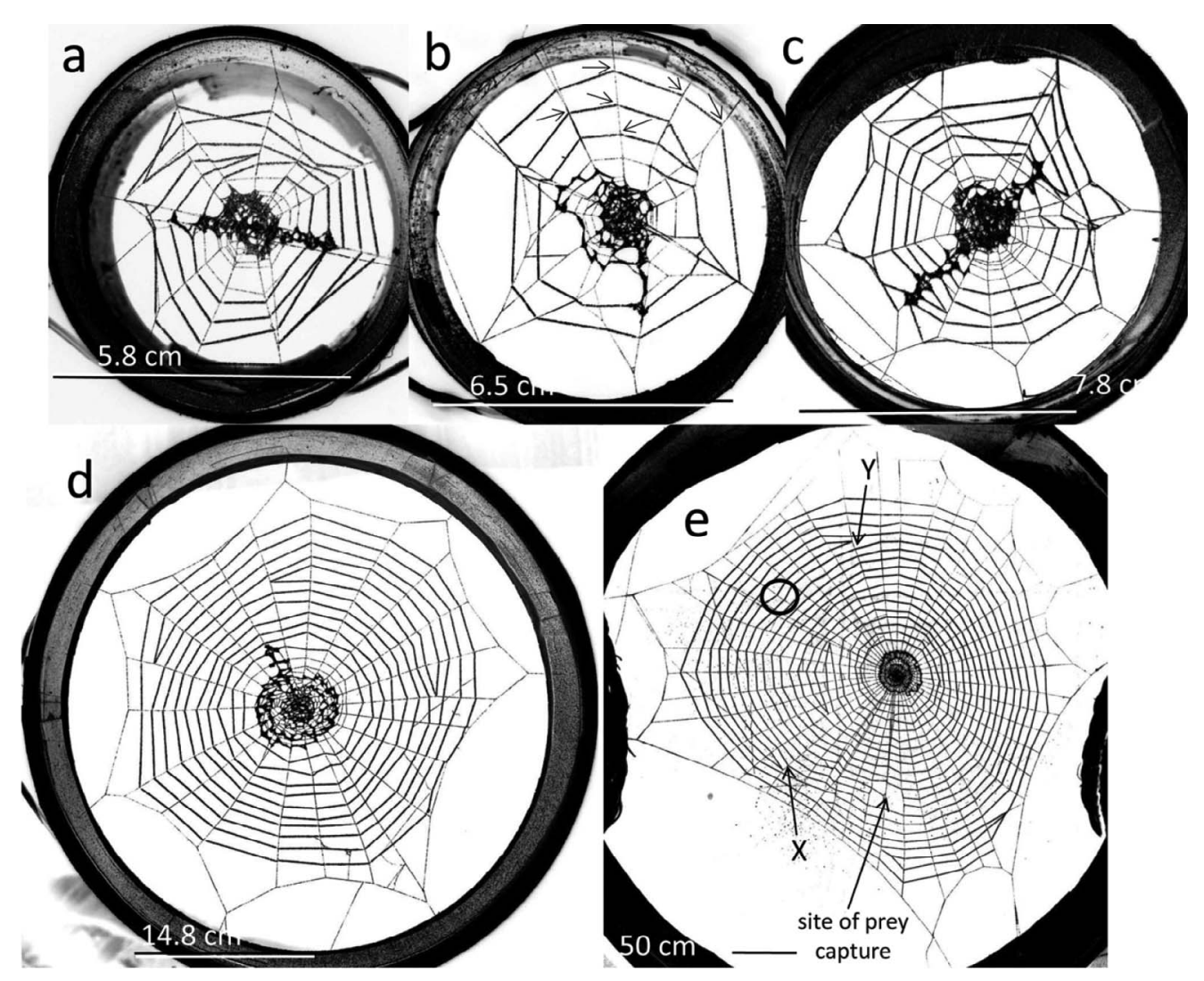

Figure 2.- Orbs built by the same mature female Z. geniculata in containers with different diameters: a) $5.8 \mathrm{~cm}$; b) $6.5 \mathrm{~cm}$; c) $7.8 \mathrm{~cm}$; d) $14.8 \mathrm{~cm}$; and e) $50 \mathrm{~cm}$. The sticky spiral lines are slightly thicker than radii and frame lines because they have more powder on them. The arrows in $b$ indicate asymmetries in the sticky line on either side of attachments to radii that reveal the direction in which the spider was circling the web (also indicated by the arrows); the sticky spiral line is thinner on the far side of the radius, probably because the spider did not comb out the first small segment of sticky cribellum lines immediately after making an attachment. The circle in e) indicates a site with a spontaneous inward deflection of the sticky spiral that offered an opportunity to test the effect of changes in the IL-TSP distance (see Figure 4). "X" indicates a spontaneous "Hingston experiment" at a turn back site, while "Y" indicates a "control" at another turn back site.

For instance, when we used experimental and unaltered control webs (fixed factors in the model) to test a possible effect but made multiple measurements of the same web, we nested measurements within webs and considered the web as a random factor within the GLMM. Most GLMM results are reported in the figures, to simplify the text. We used figures and regressions from linear models for illustrative and comparative purposes only after determining that the random factors included in GLMM had no significant effect using the Akaike information criterion (AIC). We used the R statistical Language (version 2.15.3: R Core Team 2013) for all statistical and graphical analyses.

Responses to naturally occurring deviations in the inner loop site cue.-During sticky spiral construction in unaltered webs, spiders were occasionally confronted with situations similar to that in a Hingston experiment (Fig. 1a). A naturally occurring deviation of this sort (corresponding to a "spontaneous Hingston experiment") occurred when the spider encountered a previous turn back site (Fig. 1b). Because direct observations showed that the spider's inner loop localization movements always involved tapping on the far side of the radius rather than on the near side (inset in Fig. 1b), we deduced that the spider had failed to contact the inner loop of the turn back at such a site when she was moving in the direction that she had been moving just prior to the turn back (inset in Fig. 1b). But when she moved in the opposite direction, she did contact the inner loop ("controls"). The direction the spider was moving when she encountered such a site was deduced using both the asymmetry of attachments to radii, and by tracing the path of the sticky spiral line. The spider's path during sticky spiral construction was traced in photographs of 50 webs built in large $(50 \mathrm{~cm} \mathrm{dia})$ containers by 15 females (Fig. 2e). We did not count cases in which a spider did not attach the sticky spiral to the radius where the turn back occurred. We also excluded cases in which the spider turned back after attaching to the experimental radius (the one with the previous turn back) or to either of the two adjacent radii, because turn back spaces tended to be smaller. Sample sizes were slightly different for some comparisons due to these exclusions.

We tested whether Z. geniculata uses the reference point cue from the inner loop ("IL" site) as araneoid spiders do as follows. The sticky spiral attachment to radius $r_{n}$ in Fig. $1 b$ would be expected to be displaced outward compared with attachments to radii immediately preceding and following this radius (distance $\mathrm{A}$ would be smaller than distances $\mathrm{B}$ and $\mathrm{C}$ in Fig. 1b); in addition, the outward displacement (A) would be relatively smaller or absent in control encounters compared with the distances on adjacent radii $(\mathrm{B}, \mathrm{C})$. These tests were especially powerful because they involved within web 


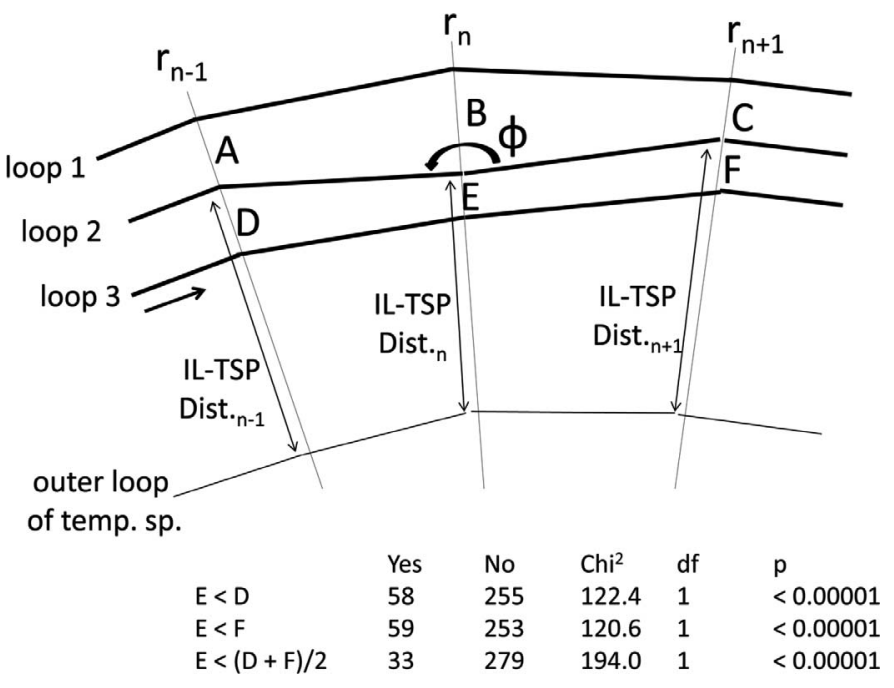

Figure 3.- Schematic drawing of the distances measured on $Z$. geniculata webs to test whether spiders used the TSP-IL distance cue. At sites in the orbs in which the inner loop of sticky spiral veered inward for one attachment (angle $\varphi$ at $r_{n}$ was $<180^{\circ}$ ), the spacing of the next loop of sticky spiral on $r_{n}$ (E) was compared with the spacing on the preceding radius ( $D$ on $r_{n-1}$ ) and on the following radius $\left(\mathrm{F}\right.$ on $\mathrm{r}_{\mathrm{n}+1}$ ). For reasons of clarity, the subsequent loops of sticky spiral are omitted; possible IL-TSP distances are shown in the drawing even though they were not measureable in the webs because the temporary spiral lines were removed by the spider during sticky spiral construction. Although IL-TSP distances were not measured directly and thus presumably only differed as depicted in the drawing on average rather than in every case, the prediction that $\mathrm{E}$ would tend to be less than both $\mathrm{D}$ and $\mathrm{F}$ was fulfilled, as indicated by the GLMM values.

comparisons that held many spider and web variables essentially constant.

Responses to naturally occurring deviations in temporary spiral distances.-We used other natural deviations that occurred during the construction of unaltered orbs in $50 \mathrm{~cm}$ dia containers to test the hypothesis that $Z$. geniculata uses the IL-TSP distance cue to guide where to attach the sticky spiral to the radius in the same way that araneoid spiders do (Eberhard \& Hesselberg 2012). As can be seen in Fig. 2e, the spaces between sticky spiral loops varied. In some cases a loop of sticky spiral was attached substantially farther from the inner loop on one radius than on the adjacent radii on either side (circle in Fig. 2e); in Fig. 3, distance B is greater than both $\mathrm{A}$ and $\mathrm{C}$, and the angle $\varphi$ on $\mathrm{r}_{\mathrm{n}}$ is less than $180^{\circ}$. When the spider arrived at such a site on her next trip around the web (e.g., to attach loop 3 to $r_{n}$ in Fig. 3), we assumed that the IL-TSP distance on $r_{n}$ tended to be smaller than the IL-TSP distances on $r_{n-1}$ or $r_{n+1}$. If the spiders were using changes in the IL-TSP distance as a cue for sticky spiral spacing as araneoids do (Eberhard \& Hesselberg 2012), then the space for loop 3 on $r_{n}$ (E in Fig. 3) was predicted to tend to be smaller than the spaces on the radii immediately preceding $(\mathrm{E}<\mathrm{D})$ and following $(\mathrm{E}<\mathrm{F})$. We tested this prediction by examining sites in which $\varphi<180^{\circ}$, and measured the distances A-F in Fig. 3. We again analyzed the data using GLMM and standardized values, so as to take into account the possible effects of multiple measurements on the same web and multiple webs of the same spiders.
Responses to naturally occurring deviations in the amount of sticky silk available.- Spiders sometimes took two nights to complete an orb, building all non-sticky lines and the outer portion of the sticky spiral on the first night, then finishing the sticky spiral on the second (Fig. 4). "Two-night" webs were built only in $50 \mathrm{~cm}$ diam containers, and never in smaller ones. If one makes the seemingly reasonable assumption that the cribellum glands fill only gradually rather than instantaneously with silk after sticky spiral silk is pulled from them (Witt et al. 1968), then on the second night the spider's cribellum glands were probably more full of silk when she resumed sticky spiral construction than they had been when she ended sticky spiral construction on the previous night. We thus used two-night webs to test the hypothesis that cribellum gland contents influence sticky spiral spacing. We marked the innermost loop of sticky spiral after the first night with small dots of talcum powder, and then photographed the web after the second night, when the spider had completed the sticky spiral (Fig. 4). We measured the spaces between all sticky spiral loops on the longest radius and on the radius most nearly opposite this radius.

Interruption of sticky spiral production occurred on the first night at different stages of sticky spiral construction: from 4 to 21 loops were built on the first night, and 5 to 19 on the second. We thus compared loops with respect to initiation and termination on a given night rather than with respect to the absolute numbers of loops. To combine data from different webs, and to control for the many variables that were not held constant and that may influence sticky spiral spacing (e.g., spider size, recent feeding experience, radius length, distance from the hub), we standardized all measurements of distances between loops by dividing each by the median space for that particular radius

Effects of changes in radius tension on sticky spiral construction.- Several possible cues that a spider might use during sticky spiral construction are physically dependent on the tensions on the radii. These include resonant vibrations of lines, vibrations transmitted from other lines, and the tensions themselves. The possible use of such tension-related cues has been tested and found to be absent in araneids (Eberhard \& Hesselberg 2012) and the uloborid Uloborus diversus Marx 1898 (Eberhard 1972) by experimentally breaking radii during sticky spiral construction. We replicated these experiments in "two-night" Z. geniculata webs in large $(50 \mathrm{~cm}$ diameter $)$ containers. Two groups of two or three radii were cut in the outer portion of the web with a scissors while the spider rested at the hub following the first night. After the spider finished the sticky spiral the second night, the web was coated and photographed (Fig. 5b). The spaces between loops that were attached to broken (lax) radii ("II" in Fig. 5) were compared with spaces between attachments to the intact radii on the near and far sides of the hole ("I" and "III" in Fig. 5), whose tension was more or less unchanged. The intra-web comparisons in these experiments again held several variables known to affect sticky spiral spacing constant or nearly constant.

Experimental reductions of the space available in which to build. - We altered the size but not the shape of the space available to the spiders in which to build their webs by housing them in different sized cylindrical or nearly cylindrical containers; the diameters at the upper end were $5.8 \mathrm{~cm}$ (a segment of 


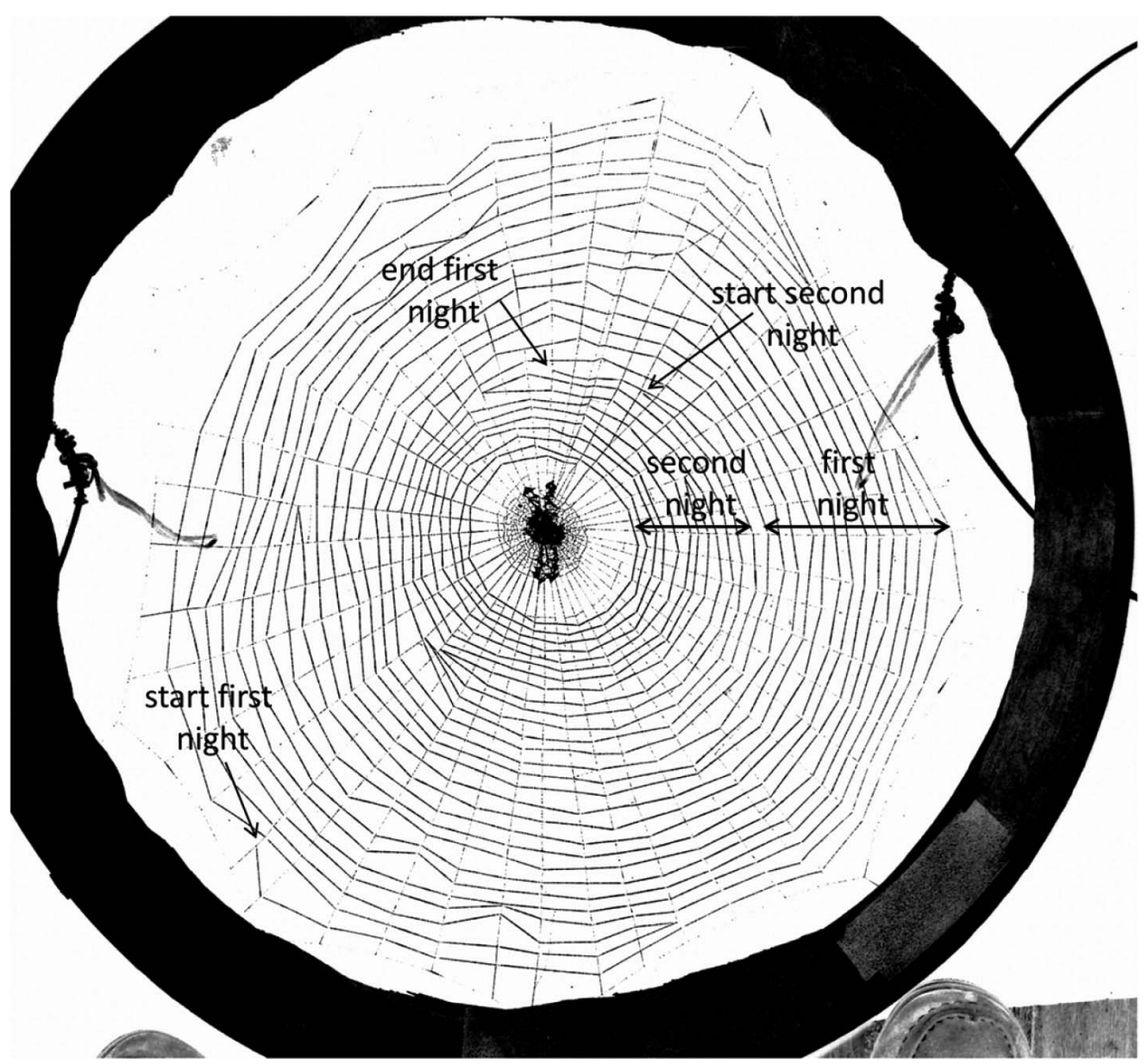

Figure 4.-A two-night web of Z. geniculata. On the first night, the hub, radii, and frame lines were all built and the spider laid the sticky spiral from the edge to the point indicated by the arrow "end first night" while moving counterclockwise. On the second night, she filled in the rest of the sticky spiral, beginning at "start second night" and moving clockwise.

PVC pipe), $6.5 \mathrm{~cm}$ (a section of a clear plastic soft drink bottle), $7.8 \mathrm{~cm}$ (a clear plastic cup for cold drinks), $14.8 \mathrm{~cm}$ (a white plastic half-gallon container), and $50 \mathrm{~cm}$ (a large plastic wash tub) (Fig. 2). The order in which an individual spider was housed in containers of different sizes varied randomly. Spiders generally built an orb within one or two days after being introduced into a container. We used the first web that a given female built in each size of container. Spiders were not fed until the end of the experiment. Nearly all females built a web in most or all of the different-sized containers, allowing for statistical comparisons in which spider identity was kept constant. In addition to the variables listed in Table 1, we measured the spaces between all adjacent loops of sticky spiral on the longest radius on which clear spaces were observable. The "span" of a web was the diameter of the container.

We calculated the "consistency" of the distances between adjacent loops of sticky spiral using a modification of the technique of Eberhard (2007). The space between each loop of sticky spiral attached to a radius ("space ${ }_{n}$ ") was compared with the space immediately previous and the space immediately following on the same radius by calculating the following ratio: $\left(\right.$ space $\left._{n}\right) /\left(\left(\right.\right.$ space $_{n-1}+$ space $\left.\left._{n+1}\right) / 2\right)$. Greater deviation of the value of this ratio from 1.0 indicated greater inconsistency. The symmetry of the web was quantified by dividing the length of the radius opposite the longest radius (distance from center of hub to frame line) by the length of longest radius of the orb (greater approximation to the maximum value 1.0 indicated greater symmetry). The total area of the web was estimated by measuring the area enclosed by the outermost loop of sticky spiral. All variables were $\log _{10}$ transformed to reduce deviation from a normal distribution, to facilitate statistical analyses; all means are followed by \pm 1 standard deviation.

We were not able to directly judge the sizes of our containers in comparison with the sizes of the areas of unrepaired $Z$. geniculata orbs in the field, because all of the field webs that we found had repaired sectors. In captivity, repair sectors were often larger than the sectors that they replaced, and "repairing" an orb is apparently a mechanism that $Z$. geniculata spiders use to expand their original orbs. Field webs often spanned spaces that were larger than the $50 \mathrm{~cm}$ diameter of our largest cages, but $50 \mathrm{~cm}$ may nevertheless be close to the typical span of a single unrepaired orb in the field. In any case, it is clear that the orbs built in our 7.8, 6.5 and $5.8 \mathrm{~cm}$ diameter containers were all unnaturally small, and thus represent challenges similar to those posed for the araneoid Leucauge argyra in a previous study (Barrantes \& Eberhard 2012). 


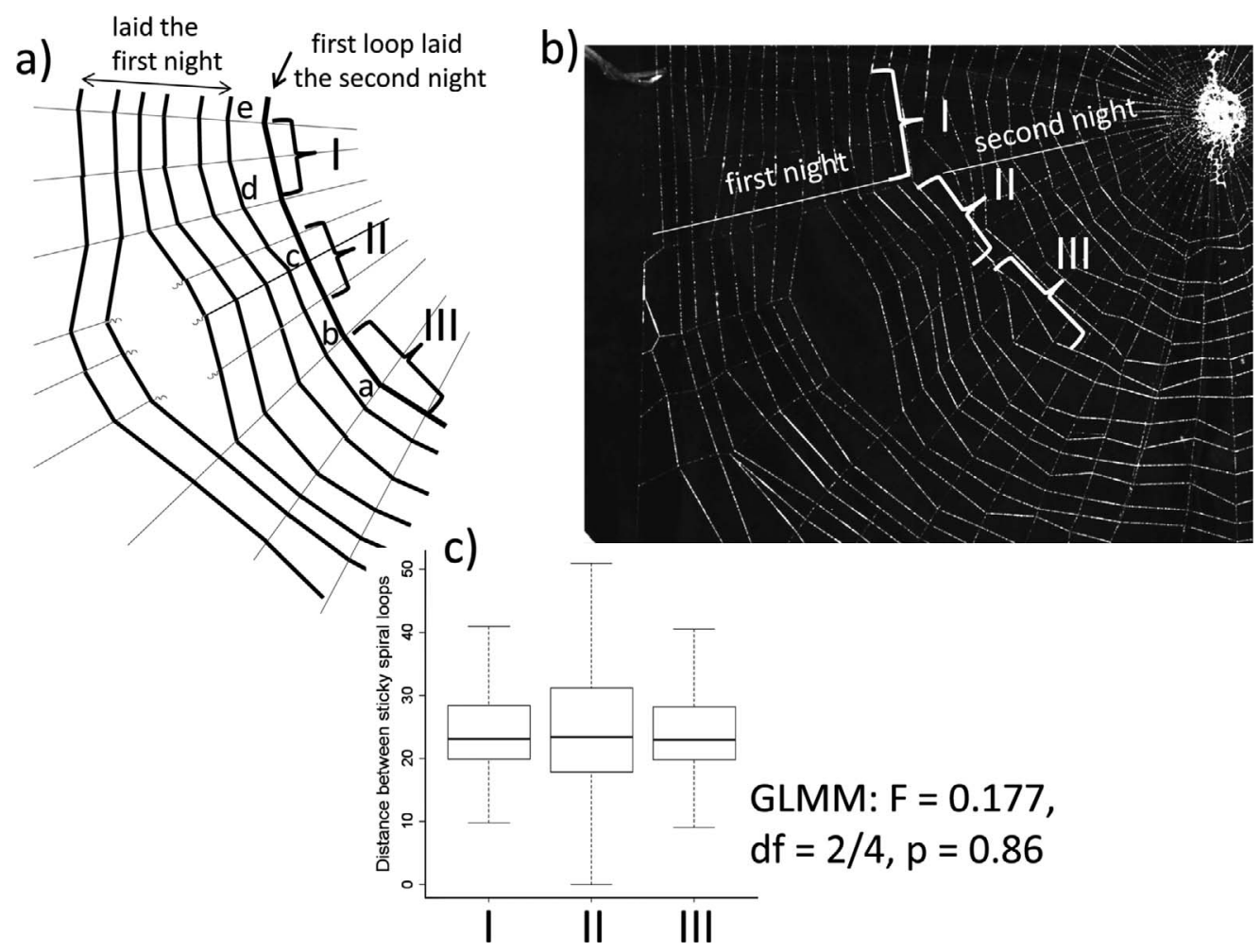

Figure 5.- a) Spaces that were measured in two-night webs that included three lax radii that were broken experimentally after the first night. The distances at which the first loop that was built the second night that crossed the three lax radii (II) and the unbroken radii that were encountered just before (I) and just following (III). b) A portion of a two-night web of a mature female of Zosis geniculata in which three radii were broken experimentally following the first night (arrows) and the spider then laid loops of sticky spiral on the second night. c) Results of the experiment: there was no effect of radius tension on the distance between loops of sticky spiral.

\section{RESULTS}

Naturally occurring deviations in the inner loop site cue.-We checked for the differences in the standardized distances between sticky spiral loops predicted by the monophyly hypothesis in 120 naturally occurring deviations in the inner loop site cue and 101 control encounters in 49 webs of $13 Z$. geniculata spiders (Fig. 6). In such "Hingston experiment equivalents", the "experimental distance" (A in Fig. 1b) showed consistent trends to be less than the distance on the previous radius (B) in $76.7 \%$ of 120 cases, and less than that on the radius immediately following (C) in $77.4 \%$ of 106 cases (Fig. 6a, c). Corresponding values for control situations were $46.5 \%$ and $48.7 \%$, and the results of the GLMM (Fig. 6b, d) indicated slightly opposite intra-web trends for control situations. Comparisons of central values for experimental and control situations showed similar trends. The mean value of $\mathrm{A}$ was significantly smaller than the mean of $\mathrm{B}$ and $\mathrm{C}$ in Hingston experiments, but not in controls (Fig. 6a-d). In sum, the sticky spiral of $Z$. geniculata tended to be displaced outward, away from the hub when these naturally occurring deviations in the inner loop site occurred.

A second clear trend was that the size of this outward displacement of the sticky line fell short of that which would have been expected if the spider were using only the inner loop site cue. Instead of $\mathrm{A}$ being 0 (as in Fig. 1a), $\mathrm{T}+\mathrm{A}$ was significantly greater than B or C (Fig. 6e, f). This trend was also predicted by the monophyly hypothesis, because this same trend also occurs in araneoids (Eberhard \& Hesselberg 2012). This trend is compatible with the hypothesis that the temporary spiral distance is an additional cue that has a negative correlation with the space between loops. This is because the tendency of the temporary distance on $r_{n}$ to be greater than those on $r_{n-1}$ or $r_{n+1}$ (see Fig. 1b) would result in $\mathrm{T}+\mathrm{A}$ being larger than $\mathrm{B}$ or $\mathrm{C}$, as was indeed found to occur.

Natural deviations in temporary spiral distance.-We made a second test of the hypothesis that the temporary spiral distance influences sticky spiral spacing in $Z$. geniculata by checking for the predicted differences in spaces in 946 cases in which $\varphi_{\mathrm{n}}$ was $<180^{\circ}$ (circle in Figs. 2e, 3) in 80 unaltered orbs built by 11 spiders. The predictions were again confirmed. The spacing of the loop of sticky spiral built when the spider had experienced a shorter temporary spiral distance (E in Fig. 3) tended to be smaller than the spacing on the radii immediately preceding (D) and following (F) (Fig. 7). In addition, there was a positive correlation between $\varphi$ on $r_{n}$ (Fig. 3) and the reduction in the standardized space on that radius (E in Fig. 3) when it was compared with the mean of the standardized spaces on the previous and the following radii $(\mathrm{E} /(\mathrm{D}+\mathrm{F}) / 2)$ (Fig. 8).

Effects of probable changes in cribellum gland contents.-The median standardized spaces between sticky spiral loops at different stages of sticky spiral construction in one and twonight webs are shown in Fig. 9. Comparisons were complicated by the fact that, as in many araneoids (e.g., Peters 1939; LeGuelte 1966; Herberstein \& Heiling 1999; Eberhard 2013), 
a)

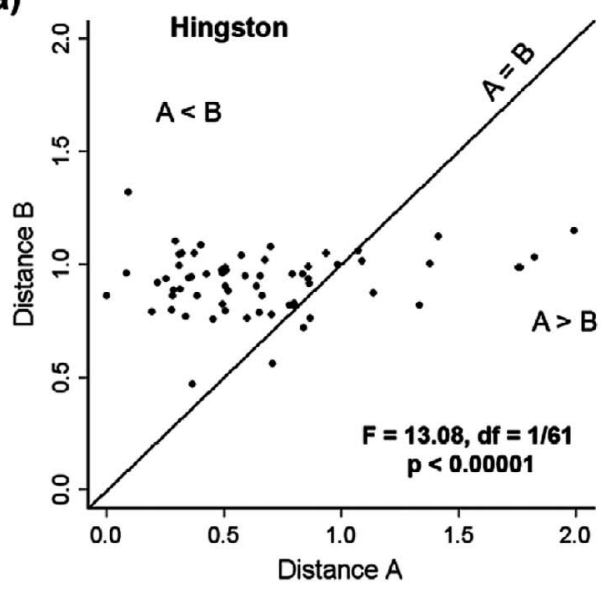

c)

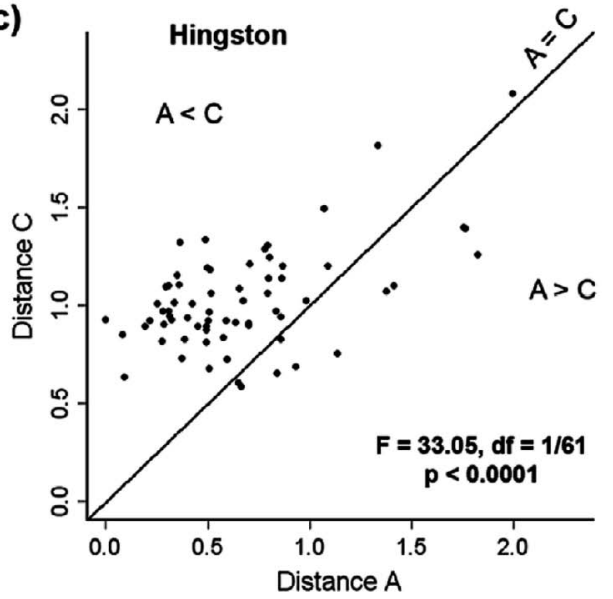

e)

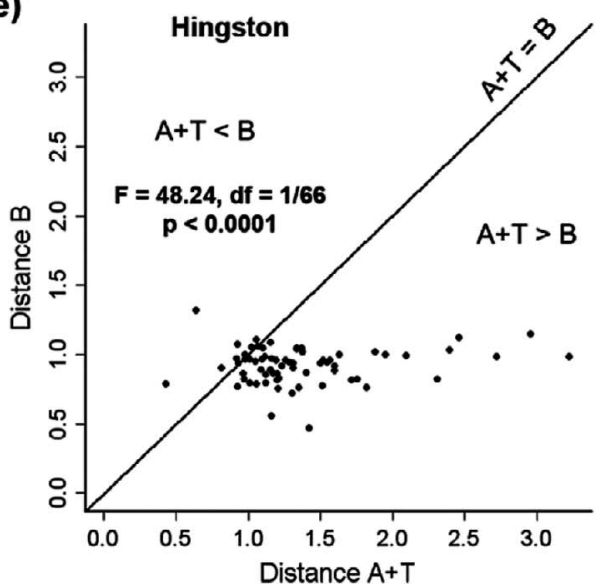

b)

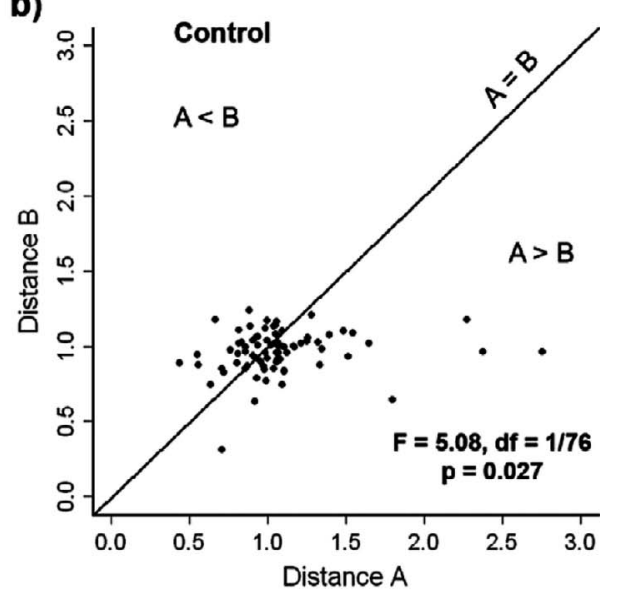

d)

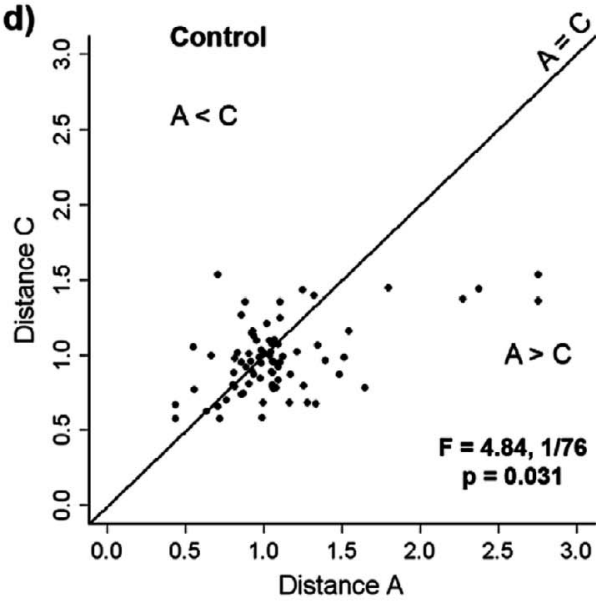

f)

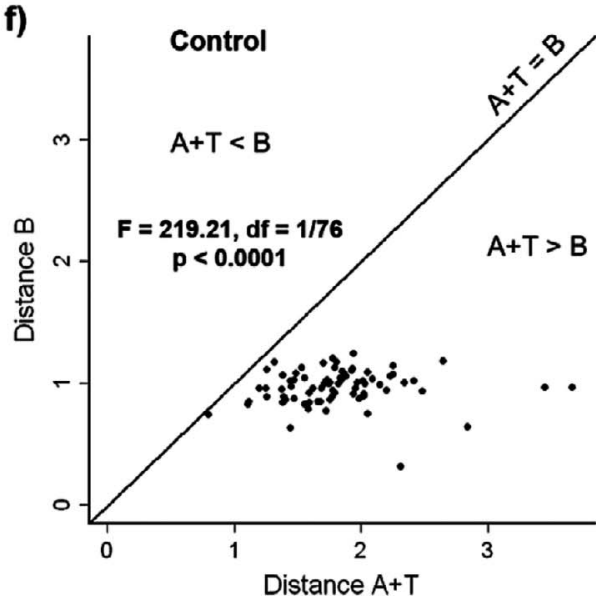

Figure 6.-Within-web comparisons of the results of spontaneous Hingston experiments and controls (letters as in Figure 1b); the line in each graph represents lack of an effect, and each dot represents a situation like that in Figure $1 \mathrm{~b}$ in which two distances are compared. As predicted if the spider is guided by the IL site cue, the experimental space tended to be smaller than the space immediately preceding it $(\mathrm{A}<\mathrm{B})$ in experiments ("Hingston") (a) than in controls ("Control") (b), and also than that immediately following it (A $<$ C) in experiments (c) but not controls (d). Contrary to the prediction if only the IL site cue is used, however, the sum of A+T tended to be greater than the preceding space (A+T $>$ B) in both experiments (e) and controls (f). This difference is in accord with the hypothesis that an additional cue (the TSP-IL distance; see Figure 3) is also used. The GLMM comparisons of the corresponding distances are indicated by $F$ values. 


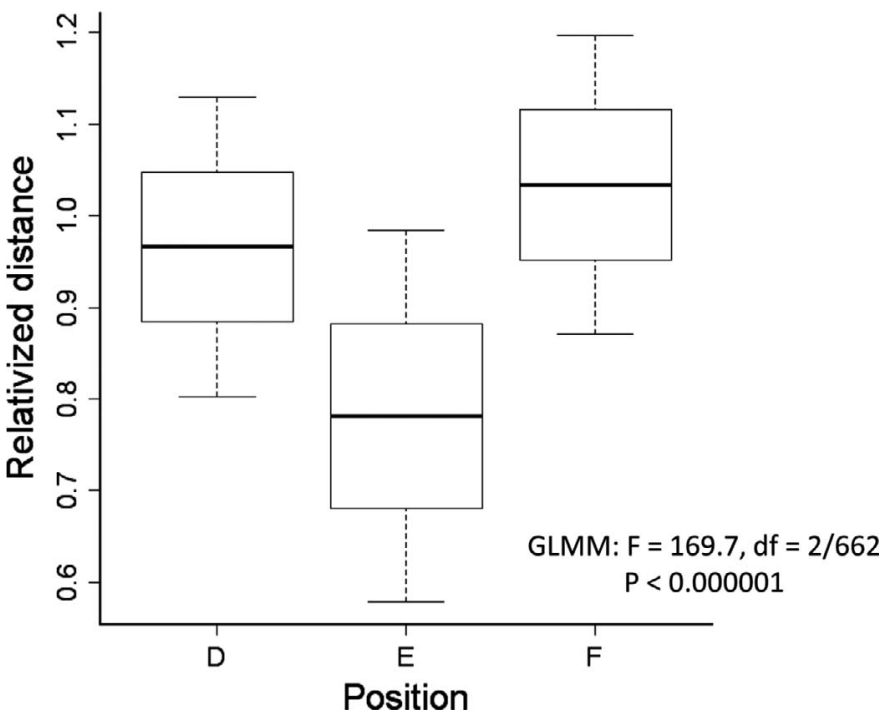

Figure 7.- There was a reduction in the standardized distance between adjacent loops of sticky spiral at a point where the inner loop of sticky spiral bent inward (E) compared with the distances of the attachments immediately preceding and following (D, F) (see Figure 3), as indicated by the GLMM analysis.

the spaces between loops of sticky spiral decreased gradually from the edge of the web toward the hub (e.g., one-night webs in Fig. 9c, d). There were two trends in two-night webs (Fig. 9a, b) that are compatible with the prediction of the monophyly hypothesis that sticky spiral spacing has a negative correlation with the amount of silk available in her cribellum glands in Z. geniculata. The spaces between the last two loops of sticky spiral that the spider laid on the first night (when her supplies of cribellum silk may have been running low) were especially large. In addition (and more importantly), the first loops that she laid at immediately adjacent sites on the same radii on the second night (when her silk supplies were likely

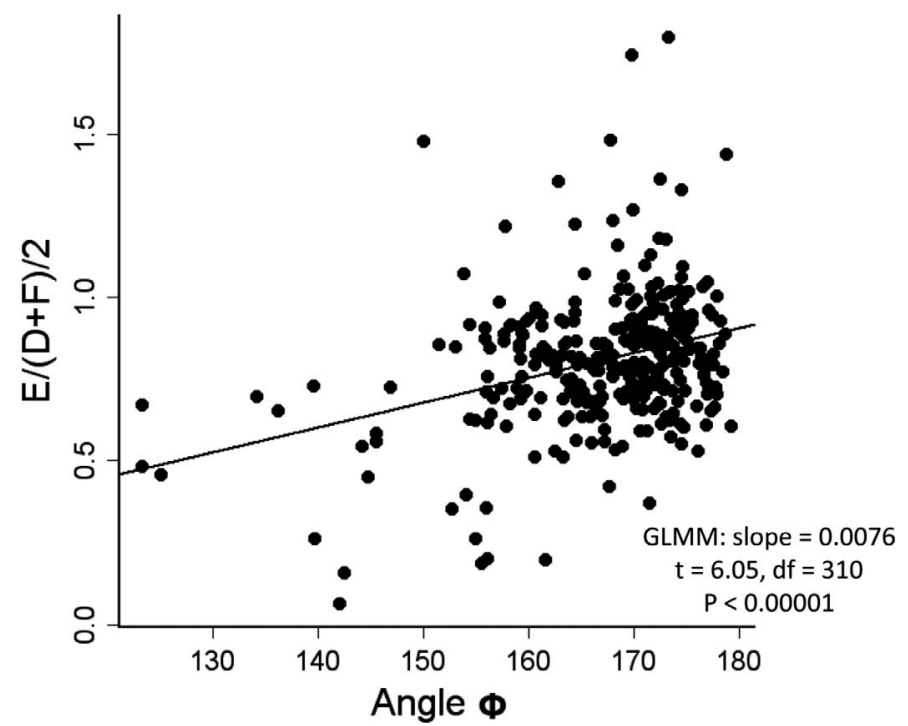

Figure 8.-There was a positive correlation between the angle at which the inner loop veered inward (angle $\phi$ in Figure 4) and the reduction in the standardized sticky spiral spacing $(\mathrm{E} /(\mathrm{D}+\mathrm{F}) / 2)$, as indicated by the GLMM values. more complete) were sharply smaller on both the longest radius (GLMM: $F=2.77$, df $=1 / 13, P<0.001$ ) and on the opposite radius (GLMM: $F=5.49$, df $=1 / 13, P<0.0001$ ) (Fig. 9a, b).

Altered tensions on radii.-The spaces between successive loops of sticky spiral attached to a lax radius which had been broken were neither consistently larger nor smaller than the preceding two spaces on intact radii nor the next two on the following intact radii (Fig. 5c). These comparisons again held constant or nearly constant several variables (spider size, distance from the hub, silk supplies) that probably influence sticky spiral spacing.

Effects of space available in which to build.--Reduced space in which to build affected multiple aspects of orb designs in Z. geniculata webs (Figs. 2, 10, Table 1). These effects were not affected by including several webs of the same spider in the GLMM models (Table 2). These effects were strikingly similar to those of similar experiments with the araneoid $L$. argyra (Barrantes \& Eberhard 2012) (Fig. 10, Table 1). All of the seven variables that are likely to be under independent behavioral control (using possibly overly-conservative criteria to judge independence; see Methods, Barrantes \& Eberhard 2012) showed similar changes in the two species when total web area changed, as predicted by the monophyly hypothesis. With the exception of two variables (web symmetry and consistency of spacing), the slopes were higher in $Z$. geniculata.

\section{DISCUSSION}

Tables 3 and 4 summarize the comparisons between cues guiding orb construction in uloborids and araneoids and the types of data on which they are based. The two groups are clearly similar. We obviously cannot claim to have documented the full diversity of cues and responses in either group. But the existence of substantial similarities confirms the prediction of the monophyly hypothesis. Within the limitations of the statistical analyses (it is not possible to disprove a null hypothesis of lack of difference, but only to demonstrate that it is improbable), the differences in the stimuli and responses to them in the two groups predicted by the polyphyly hypothesis did not occur. We discuss detailed comparisons below.

Reference stimuli that guide sticky spiral placement.-Inner loop site and temporary spiral distance cues: The uloborid $Z$. geniculata resembles araneoids both in sensing IL site and TSP-IL distance cues, and in responding to these cues in a similar manner. Thus $Z$. geniculata resembles the araneoids in sensing the IL site, and in responding to an outward displacement of this site by displacing the attachment of her sticky spiral outward. The attachment of the sticky line to the radius was displaced outward in the naturally occurring deviations in the inner loop cue (the "spontaneous Hingston experiments") in Z. geniculata, just as occurs in all four araneoids that have been tested (Hingston 1920; Peters 1954; Eberhard \& Hesselberg 2012). These cues are available to the spiders because, as in araneids, uloborid spiders use leg oI to locate the IL site (Eberhard 1982).

In addition, the outward deflection in "spontaneous Hingston experiments" was less than would have been predicted if the IL site were the only reference stimulus (as 
TWO NIGHTS

a)

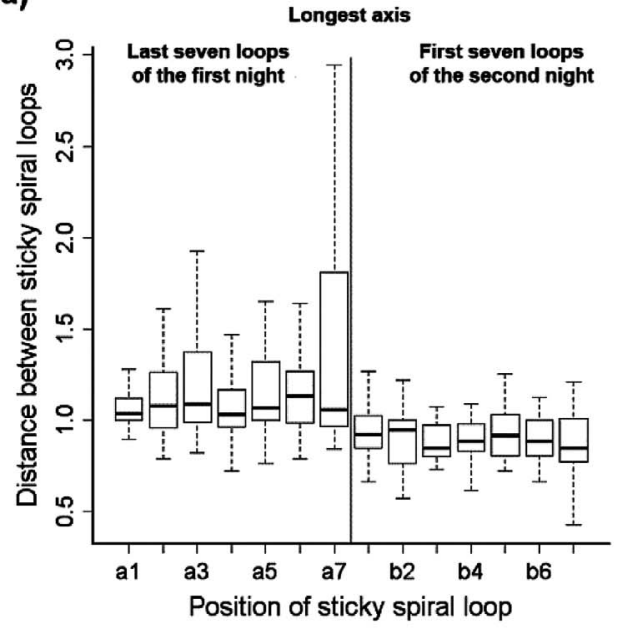

b)

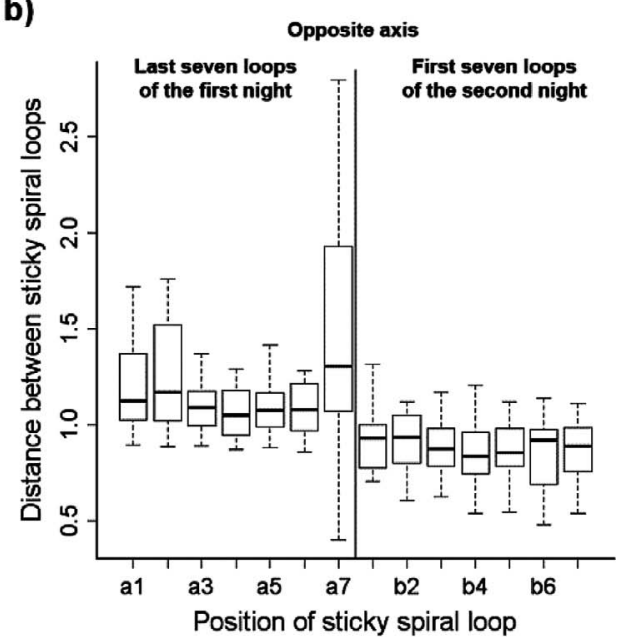

ONE NIGHT

c)

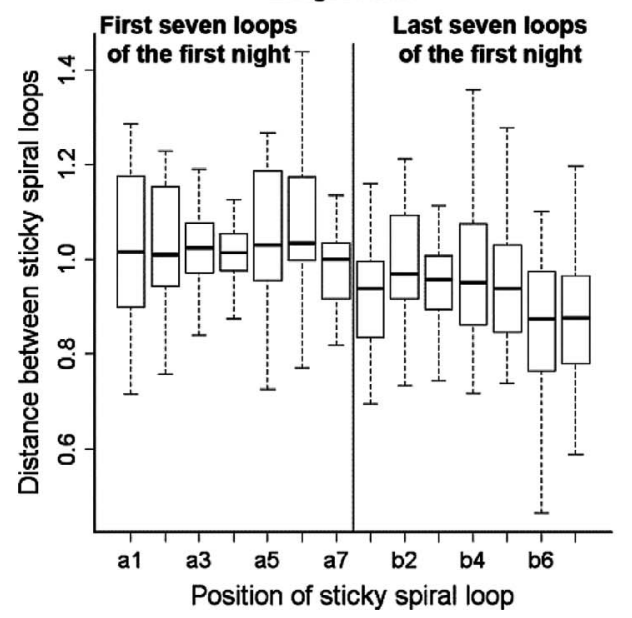

d)

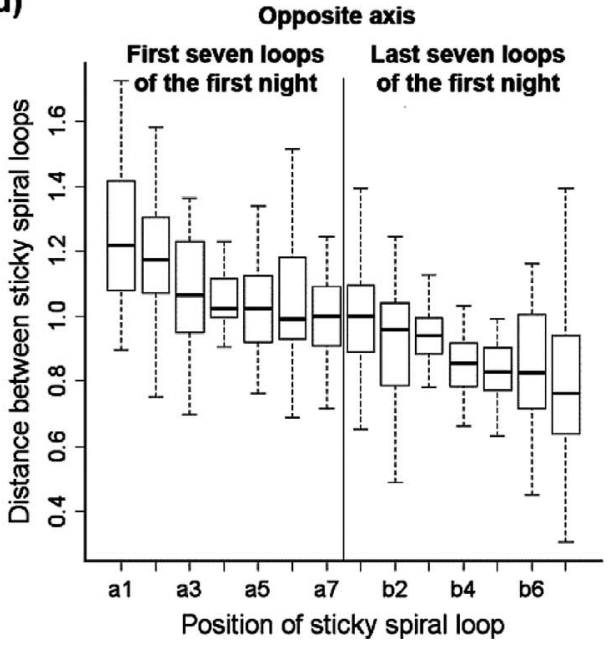

Figure 9.- The distances (medians, quartiles and ranges) of the standardized spaces between successive sticky spiral loops in orbs built by $Z$. geniculata over two nights (above) decreased abruptly in the first seven loops of the second night, both on the longest radius and the opposite radius. In webs built in a single night (below), the means decreased gradually along the entire length of each of these two radii. Measurements from different single night orbs that had different total numbers of sticky spiral loops are combined by plotting the first seven (a1 to a7) and the last seven spaces (b1 to b7) in each web (all measurements in both two-night and one-night webs were standardized by dividing by the median value for the entire radius).

was supposed by Hingston 1920). These "incomplete" responses to inner loop site cues, which are probably due to the use of a second, TSP-IL distance cue (Eberhard \& Hesselberg 2012), were very similar to those observed in the araneoids $M$. duodecimspinosa (O. P.-Cambridge 1890) and $L$. mariana (Taczanowski 1881) (and may have also occurred in Neoscona nautica) (Eberhard \& Hesselberg 2012).

The hypothesis that $Z$. geniculata uses the TSP-IL cue was also supported by a second pattern in their webs. When the inner loop on one radius was displaced inward substantially with respect to attachments on adjacent radii (B compared with $\mathrm{A}$ and $\mathrm{C}$ in Fig. 3), the spacing of the next loop of sticky spiral (E) tended to be reduced. The same pattern of "compensatory" spacing occurs in the orbs of the araneoids M. duodecimspinosa, L. mariana and Allocyclosa bifurcata (McCook 1887) (Eberhard 2011; Eberhard \& Hesselberg 2012). It probably results from their also using the TSP-IL distance to guide sticky spiral placement (Eberhard \& Hesselberg 2012).

Still another indication that both uloborids and araneoids use the site of the outer loop of temporary spiral in determining attachment sites of the sticky spiral comes from observations of the placement of the first, outermost loop of sticky spiral. In the uloborid U. diversus (Eberhard 1972) and 

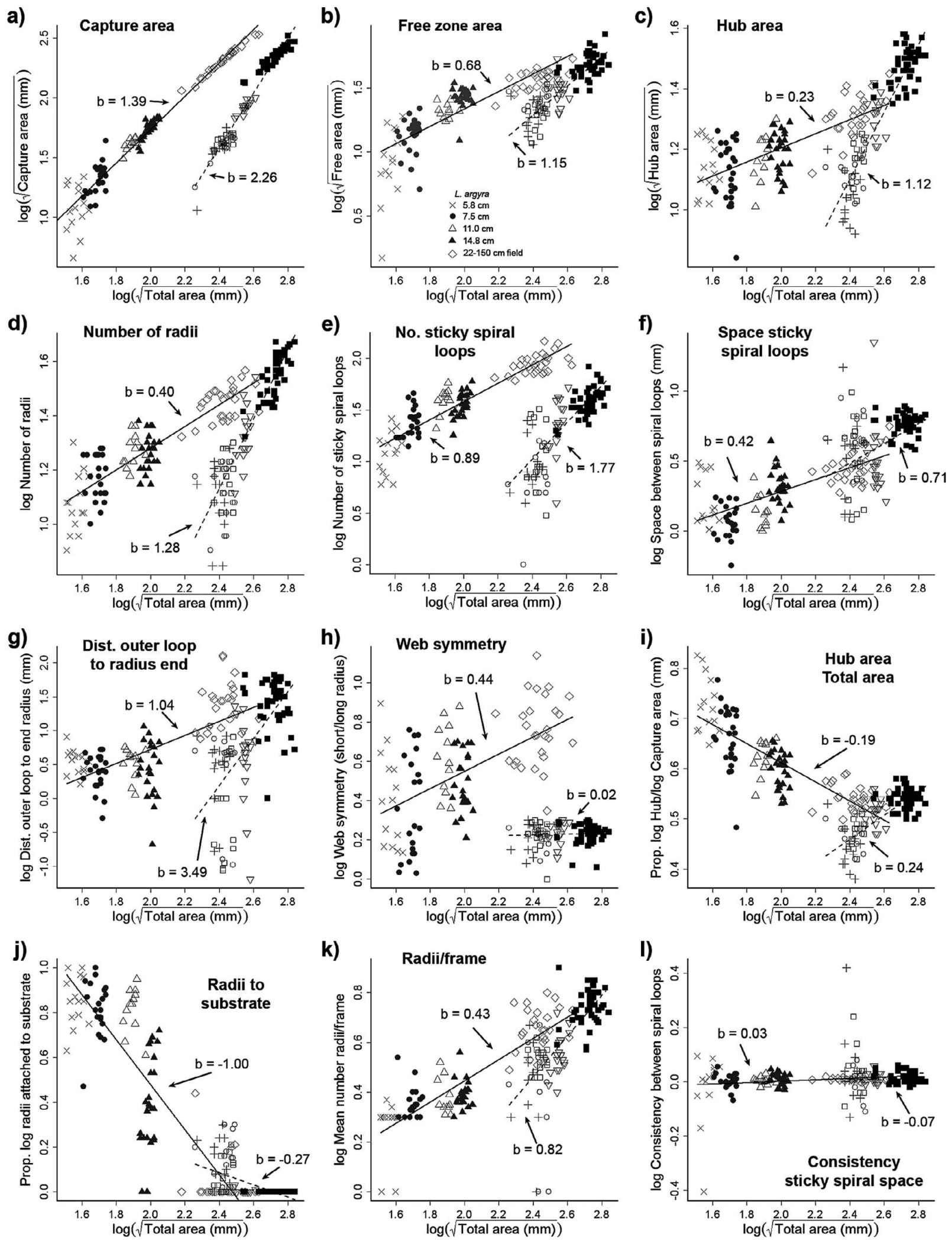

Figure 10.-Relationships between different aspects of web design and the total area of webs of Z. geniculata (solid line) and of the larger tetragnathid L. argyra (dotted line) (from Barrantes \& Eberhard 2012) that were built in containers with different diameters (most were smaller than the sizes of the normal orbs of that species). The absolute values of slopes varied between species, but their signs and even the degree of dispersion around the regression lines were similar in most cases. 
Table 2.- Results of the mixed effects models for 18 web features of Zosis geniculata (dependent variables). The total area of the web was in all cases the predictor variable. In one model, individual spiders were included as a random factor (model with random effects); in a second model, individual spiders were not considered as a random effect. Results obtained with both models were very similar as indicated by the values of the Akaike Information Criterion (AIC) included for both models. The asterisks indicate the significance associated to the effect of the intercept or the slope on each dependent variable: ${ }^{*} P<0.05,{ }^{*} P<0.001,{ }^{* * *} P<0.0001$. All variables were $\log 10-$ transformed. $\mathrm{L}$ indicates longest radius and areas are given as the square root of the actual values.

\begin{tabular}{|c|c|c|c|c|c|c|c|c|c|c|}
\hline \multirow[b]{3}{*}{ Variable } & \multicolumn{4}{|c|}{ Model with random effects (1) } & \multicolumn{4}{|c|}{ Model without random effects (2) } & \multirow[b]{3}{*}{$\mathrm{AIC}_{(1)}$} & \multirow[b]{3}{*}{$\mathrm{AIC}_{(2)}$} \\
\hline & \multicolumn{2}{|c|}{ Intercept } & \multicolumn{2}{|c|}{ Slope (total area) } & \multicolumn{2}{|c|}{ Intercept } & \multicolumn{2}{|c|}{ Slope (total area) } & & \\
\hline & Estimate & SE & Estimate & SE & Estimate & $\mathrm{SE}$ & Estimate & SE & & \\
\hline Capture area & $-3.92 * * *$ & 0.112 & $2.29 * * *$ & 0.043 & $-3.92 * * *$ & 0.112 & $2.29 * * *$ & 0.044 & -274.3 & -276.26 \\
\hline Free zone & $-1.48 * * *$ & 0.182 & $1.15 * * *$ & 0.071 & $-1.48 * * *$ & 0.182 & $1.15^{* * *}$ & 0.071 & -161.71 & -163.71 \\
\hline Hub area & $-1.58 * * *$ & 0.129 & $1.12 * * *$ & 0.05 & $-1.57 * * *$ & 0.129 & $1.12 * * *$ & 0.05 & -242.92 & -244.92 \\
\hline Number of radii & $-1.94 * * *$ & 0.15 & $1.28 * * *$ & 0.058 & $-1.93 * * *$ & 0.153 & $1.28 * * *$ & 0.06 & -202.59 & -203.78 \\
\hline $\begin{array}{l}\text { No. sticky spiral } \\
\text { loops }\end{array}$ & $-3.36^{* * *}$ & 0.429 & $1.72 * * *$ & 0.162 & $-3.44 * * *$ & 0.384 & $1.74 * * *$ & 0.149 & 1.24 & 6.75 \\
\hline Sticky spiral spaces L & $-1.23 * *$ & 0.361 & $0.71 * * *$ & 0.141 & $-1.22 * *$ & 0.362 & $0.71^{* * *}$ & 0.141 & -2.45 & -4.44 \\
\hline Consistency L & 0.21 & 0.135 & -0.08 & 0.05 & 0.2 & 0.105 & -0.07 & 0.04 & -278.82 & -280.72 \\
\hline Dist. from outer loop & $-8.19^{* * *}$ & 0.982 & $3.49 * * *$ & 0.382 & $-8.18^{* * *}$ & 0.982 & $3.49 * * *$ & 0.382 & 228.79 & 226.79 \\
\hline $\begin{array}{l}\text { Length longest } \\
\text { radius }\end{array}$ & $-5.73 * * *$ & 0.236 & $2.85^{* * *}$ & 0.091 & $-5.70 * * *$ & 0.242 & $2.85 * * *$ & 0.094 & -98.26 & -99.05 \\
\hline $\begin{array}{l}\text { Length shortest } \\
\text { radius }\end{array}$ & $-5.48^{* * *}$ & 0.276 & $2.71 * * *$ & 0.107 & $-5.41 * * *$ & 0.3 & $2.67 * * *$ & 0.117 & -52.54 & -48.36 \\
\hline Web symmetry & 0.18 & 0.092 & 0.02 & 0.036 & $0.18^{*}$ & 0.092 & 0.02 & 0.036 & -320.32 & -322.32 \\
\hline $\begin{array}{l}\text { Prop. radii attached } \\
\text { to substrate }\end{array}$ & $0.71^{* * *}$ & 0.13 & $-0.26^{* * *}$ & 0.05 & $0.73 * * *$ & 0.114 & $-0.27 * * *$ & 0.044 & -273.56 & -268.35 \\
\hline $\begin{array}{l}\text { Prop. frame w. single } \\
\text { radius }\end{array}$ & $0.56 * *$ & 0.142 & $-0.20 * * *$ & 0.054 & $0.58 * *$ & 0.128 & $-0.21 * * *$ & 0.05 & -243.13 & -242.49 \\
\hline Mean radii/frame & $-1.48 * * *$ & 0.211 & $0.81 * * *$ & 0.081 & $-1.50 * * *$ & 0.191 & $0.82 * * *$ & 0.074 & -154.61 & -153.32 \\
\hline $\begin{array}{l}\text { Number of frame } \\
\text { lines }\end{array}$ & $-1.03 * *$ & 0.301 & $0.73 * * *$ & 0.117 & $-1.03 * * *$ & 0.301 & $0.73 * * *$ & 0.117 & -45.44 & -47.44 \\
\hline $\begin{array}{l}\text { Prop. capture area/ } \\
\text { total area }\end{array}$ & $-0.77 * * *$ & 0.046 & $0.60 * * *$ & 0.018 & $0.77 * * *$ & 0.046 & $0.60 * * *$ & 0.018 & -481.74 & -483.74 \\
\hline $\begin{array}{l}\text { Prop. free zone area/ } \\
\text { total area }\end{array}$ & 0.01 & 0.073 & $0.22 * * *$ & 0.028 & 0.01 & 0.073 & $0.22 * * *$ & 0.029 & -372.86 & -374.86 \\
\hline $\begin{array}{l}\text { Prop. hub area/total } \\
\text { area }\end{array}$ & $-0.12^{*}$ & 0.05 & $0.24 * * *$ & 0.019 & $-0.12^{*}$ & 0.051 & $0.24 * * *$ & 0.02 & -456.44 & -458.43 \\
\hline
\end{tabular}

in the araneids Araneus diadematus Clerck 1757 (Zschokke 1993) and M. duodecimspinosa (Eberhard 2012) the location of the first loop of sticky spiral is correlated with the position of the outermost loop of temporary spiral.

In sum, the uloborid shows a detailed similarity with araneoids regarding use of and responses to two different reference stimuli during sticky spiral construction.

Tensions on radii: Neither the two uloborids, Uloborus diversus (Eberhard 1972) and Z. geniculata, nor the araneoids, L. mariana, M. duodecimspinosa (Eberhard \& Hesselberg 2012), showed any changes in sticky spiral spacing in response to sharp experimental reductions in radius tension. The implication is that many alternative, tension-dependent cues that could be used to guide sticky spiral placement (e.g., resonant vibrations of radii, vibrations of other lines, resistance when pulled, and tensions) are not used in either the uloborid or in araneoids, supporting the monophyly hypothesis.

General settings stimuli that guide sticky spiral placement.Amount of sticky silk available: The spiders in both groups sense the amount of silk present in sticky silk glands (cribellum and pseudoflagelliform glands in uloborids, aggregate and flagelliform glands in araneoids), and they increase the sticky spiral spacing when they have less silk available. The spaces between loops of sticky spiral in the two-night webs of $Z$. geniculata correlated negatively with the amount of sticky silk thought to be available to the spiders in their silk glands, and these resemble similar negative correlations in araneoids (Eberhard 1988b). Direct experimental manipulation of gland contents has not been performed in either group, however, so correlations with other stimuli might be involved. In sum, as far as the experiments go, the resemblance in the two groups supports the monophyly hypothesis.

Reduced spaces in which to build. - When the spiders were experimentally confined in small spaces of different sizes, there was a striking similarity between the several responses of $Z$. geniculata and those of the araneoid L. argyra (Fig. 10, Table 1). Of the 12 relations to total area in Fig. 10, ten are quite similar. The specific cues that triggered these responses are not known in either species, so the possibility that some similarities in the graphs are due to the use of different cues cannot be eliminated. Nevertheless, as far as the experiments go, these similarities are again in accord with the monophyly hypothesis.

It is probable that some of the responses illustrated in Fig. 10 are correlated and not independent of each other, so the number of valid comparisons is probably lower than suggested in the figure. Using the common sense criteria for independence proposed by Barrantes \& Eberhard (2012) (see 
Table 3.-Comparisons of the polarities of changes in webs built in more constrained spaces (e.g., smaller containers) by Zosis geniculata (Uloboridae), and by Leucauge argyra (Tetragnathidae) (data from Barrantes \& Eberhard 2012). Changes that can be attributed to simple physical limitations imposed by smaller available spaces, and are not appropriately considered to be due to decisions by the spiders are marked with "*". Variables that are likely to reflect independent decisions by the spider (using conservative criteria - see methods and Barrantes \& Eberhard 2012) are preceded by different letters. Some variables, whose cause and effect relations with respect to cues and responses may be more complex, are not labeled.

\begin{tabular}{|c|c|c|}
\hline & Z. geniculata & L. argyra \\
\hline \multicolumn{3}{|l|}{ Radii, frames, anchor lines } \\
\hline $\boldsymbol{A}$ Number of frame lines & smaller $^{1,2}$ & smaller $^{1,2}$ \\
\hline \multicolumn{3}{|l|}{$\boldsymbol{A}$ Proportion of radii attached directly } \\
\hline to the substrate & greater & greater \\
\hline \multicolumn{3}{|l|}{$A$ Proportion of frame lines with only } \\
\hline$A$ Number of radii/frame line & smaller & smaller \\
\hline \multicolumn{3}{|l|}{$\begin{array}{l}A \text { Proportion of radii that end on "V" } \\
\text { frame lines }\end{array}$} \\
\hline $\boldsymbol{B}$ Number of radii & smaller & smaller \\
\hline$*$ Length of radii & smaller & smaller \\
\hline \multicolumn{3}{|l|}{ Relative areas } \\
\hline *Capture area & smaller & smaller \\
\hline$C$ Hub area & smaller & smaller \\
\hline $\boldsymbol{D}$ Symmetry & $?$ & greater \\
\hline $\boldsymbol{E}$ Free zone area & smaller?* & smaller \\
\hline Free zone area/total area & greater & greater \\
\hline Hub area/total area & greater & greater \\
\hline \multicolumn{3}{|l|}{ Hub } \\
\hline$C$ Number loops hub spiral & $?^{3}$ & no change ${ }^{2}$ \\
\hline$C$ Space between hub loops & $?^{4}$ & \\
\hline Circular stabilimentum loops & less frequent & $-{ }^{5}$ \\
\hline \multicolumn{3}{|l|}{ Sticky spiral } \\
\hline \multicolumn{3}{|l|}{$\begin{array}{l}\boldsymbol{F} \text { Space between loops of sticky spiral } \\
\text { on longest radius }\end{array}$} \\
\hline $\begin{array}{l}\boldsymbol{G} \text { Distance from outer loop of sticky } \\
\text { spiral to end of radius }\end{array}$ & smaller & smaller \\
\hline Number of loops of sticky spiral & smaller & smaller \\
\hline $\begin{array}{l}\boldsymbol{E} \text { Distance from outer loop of hub to } \\
\text { inner loop of sticky spiral (free zone) }\end{array}$ & smaller $^{2}$ & smaller $^{2}$ \\
\hline Consistency of sticky spiral spacing on & & \\
\hline longest radius & no change & no change \\
\hline
\end{tabular}

${ }^{1}$ In both species, the positive relationship with total web area was only significant in the four smallest containers, and in the largest space the number of frames did not increase.

${ }^{2}$ Unpublished data, G. Barrantes \& W. Eberhard.

${ }^{3}$ Inner portions of hub could not be distinguished due to the stabilimentum.

${ }_{5}^{4}$ Outermost loops only (inner loops were not generally distinguishable).

${ }^{5}$ No stabilimentum built in this species.

Methods), there were seven different types of responses to small spaces (Tables 1, 3); the two groups resemble each other in all of them.

The most striking uloborid-araneoid difference in Fig. 10 is the positive relationship between the proportion of the area occupied by the hub to the total area in $Z$. geniculata (Fig. 10i), as compared with the negative relationship between these variables in L. argyra; at the same time, the absolute value of hub area was smaller in smaller webs in both species (Fig. 10c). The difference may be related to the "launching platform" function of the hub for attacks on prey (Briceño \&
Eberhard 2011). The diameters of the hubs of normal webs are substantially greater than the length of the spider in $Z$. geniculata, but are substantially less than the length of the spider in L. argyra (counting her legs). Thus in Z. geniculata, proportionally larger reductions in hub area are feasible that will still leave the hub large enough for the spider to turn and find lines to grasp with her legs III and IV which support her during an attack (Briceño \& Eberhard 2011).

One response to small spaces (reduced web symmetry in smaller spaces) occurred only in L. argyra but not $Z$. geniculata (Fig. 11h). Web symmetry is determined early in orb construction, when the location of the hub is first established (Eberhard 1990; Vollrath 1992), but the cue (or cues) used by spiders at this stage that determine the site of the hub are very poorly known.

Other comparisons. - The spaces between sticky spiral lines are larger near the edge of typical one-night orbs of $Z$. geniculata than near the hub (Figs. 4, 9). Similar patterns in sticky spiral spacing occur in the webs of many araneoids (LeGuelte 1966; Herberstein \& Heiling 1999; Eberhard 2013). The specific cue (or cues) used by the spider to sense her position on the web with respect to the hub is not known in either uloborids or araneoids, but the similarity in the trends also favors the monophyly hypothesis.

One trend documented in the space manipulation experiments with both $Z$. geniculata and L. argyra (A in Table 3) also extends to the normal webs of species in other araneoid families that build in very small spaces in the leaf litter, or have secondarily lost their orbs. Frame lines are less common and have fewer radii attached to them in the anapid Anapisona simoni Gertsch 1941 (Eberhard 2007, 2011) and the araneid Paraneus cyrtoscapus (Pocock 1898) in webs built in deep grass (Edmunds 1978), and are completely lacking or reduced to very short lines bearing only a single radius in the webs of the anapids Comaroma simoni Bertkau 1889 (Kropf 1990) and Conoculus lyugadinus Komatsu 1940 (Shinkai \& Shinkai 1988), and the mysmenid Trogloneta granulum Simon 1922 (Hajer 2000; Hajer \& Řeháková 2003). The responses of $L$. argyra and $Z$. geniculata to experimental reductions in available space thus resemble evolutionary responses to similarly reduced spaces in other araneoid groups, emphasizing the apparent generality of this response throughout araneoid orb weavers.

Diversity within araneoids. - The variation among araneoids with respect to some of the cues and responses employed in orb construction was greater than the minor differences in uloborid-araneoid comparisons. Araneoids locate the site of the inner loop of sticky spiral during sticky spiral construction in a variety of ways: nephilids and a few araneids use leg oIV; and tetragnathids use leg iI (Eberhard 1982; Kuntner et al. 2008). On the other hand, most araneids and all uloborids use leg oI (e.g., Fig. 1b inset). The responses to the IL site as a reference cue that are shared by araneoids and uloborids have apparently been secondarily lost in some araneoids, including those in the derived araneoid families Theridiosomatidae, Anapidae, Symphytognathidae, and Mysmenidae (Eberhard 1982, 1987). Compensatory alterations in sticky spiral spacing in finished webs suggest that these derived families instead rely entirely on the temporary spiral distance 


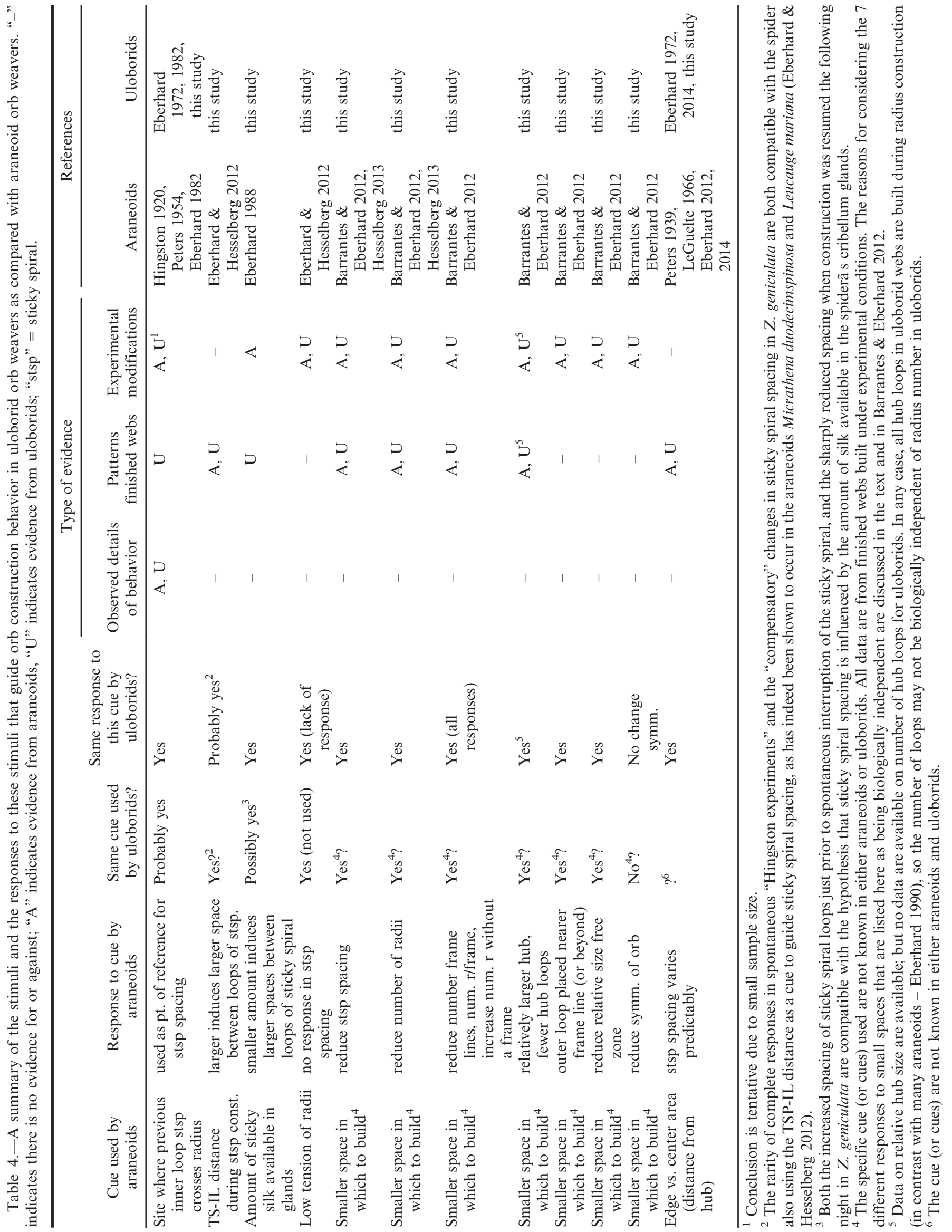


cue (or the distance from the hub in the groups in which there is no temporary spiral) (Eberhard 2011).

In sum, the cues that guide sticky spiral placement show as much or more diversity within araneoids as they do when comparing araneoids with uloborids. This emphasizes the strength of the support for the orb web monophyly hypothesis.

Implications for phylogenies.-Recent molecular studies (Fernández et al. 2014, Bond et al. 2014) suggested that there are two likely alternatives: the orb web either evolved earlier than previously hypothesized, and is ancestral for a majority of spiders, including those in the RTA clade; or else it had multiple, independent origins, as was hypothesized by precladistic authors. The behavioral characters examined in the present study support the first of these alternatives.

\section{ACKNOWLEDGMENTS}

We thank Ingi Agnarsson, an anonymous reviewer, and Matjaz Kuntner for useful comments, Robert Suter for considerate handling of the manuscript, and the Smithsonian Tropical Research Institute and the Vicerectoría de Investigación of the Universidad de Costa Rica for financial support.

\section{LITERATURE CITED}

Agnarsson, I., M. Gregorič, T.A. Blackledge \& M. Kuntner. 2013. The phylogenetic placement of Psechridae within Entelegynae and the convergent origin of orb-like spider webs. Journal of Zoological and Systematic Evolutionary Research 51:100-106.

Atz, J.W. 1970. The application of the idea of homology to behavior. Pp. 17-48. In Development and Evolution of Behavior. (L.R. Aronson, E. Tobach, D.S. Lehrman, J.S. Rosenblatt, eds.). Freeman, San Francisco.

Barrantes, G. \& W.G. Eberhard. 2007. The evolution of preywrapping behaviour in spiders. Journal of Natural History 41:1631-1658.

Barrantes, G. \& W.G. Eberhard. 2012. Extreme behavioral adjustments by an orb-web spider to restricted spaces. Ethology 118:1-12.

Bayer, S. 2011. Revision of the pseudo-orbweavers of the genus Fecenia Simon, 1887 (Araneae, Psechridae), with emphasis on their pre-epigyne. Zookeys 153:1-56.

Blackledge, T.A., N. Scharff, J.A. Coddington, T.S. Szu, J. Wenzel \& C.Y. Hayashi et al. 2009. Reconstructing web evolution and spider diversification in the molecular era. Proceedings of the National Academy of Science (USA) 13:5229-5234.

Bond, J.E., N.L. Garrison, C.A. Hamilton, R.L. Godwin, M. Hedin \& I. Agnarsson. 2014. Phylogenomics resolves a spider backbone phylogeny and rejects a prevailing paradigm for orb web evolution. Current Biology 24:1765-1771.

Briceño, R.D. \& W.G. Eberhard. 2011. The hub as a launching platform: rapid movements of the spider Leucauge mariana (Araneae: Tetragnathidae) as it turns to attack prey. Journal of Arachnology 39:102-112.

Coddington, J.A. 1986. The monophyletic origin of the orb web. Pp. 319-363. In Spiders Webs Behavior and Evolution. (W.A. Shear, ed.). Stanford Univ. Press, Palo Alto, California.

Dimitrov, D., L. Lopardo, G. Giribet, M.A. Arnedo, F. ÁlvarezPadilla \& G. Hormiga. 2012. Tangled in a sparse spider web: single origin of orb weavers and their spinning work unraveled by denser taxonomic sampling. Proceedings of the Royal Society B 279:1341-1350.

Eberhard, W.G. 1972. The web of Uloborus diversus (Araneae: Uloboridae). Journal of Zoology 166:417-465.
Eberhard, W.G. 1977. 'Rectangular orb' webs of Synotaxus (Araneae: Theridiidae). Journal of Natural History 11:501-507.

Eberhard, W.G. 1982. Behavioral characters for the higher classification of orb-weaving spiders. Evolution 36:1067-1095.

Eberhard, W.G. 1987. Web-building behavior of anapid, symphytognathid and mysmenid spiders (Araneae). Journal of Arachnology 14:339-356.

Eberhard, W.G. 1988a. Memory of distances and directions moved as cues during temporary spiral construction in the spider Leucauge mariana (Araneae: Araneidae). Journal of Insect Behavior 1:51-66.

Eberhard, W.G. 1988b. Behavioral flexibility in orb web construction: effects of supplies in different silk glands and spider size and weight. Journal of Arachnology 16:295-302.

Eberhard, W.G. 1990. Early stages of orb construction by Philoponella vicinia, Leucauge mariana, and Nephila clavipes (Araneae, Uloboridae and Tetragnathidae), and their phylogenetic implications. Journal of Arachnology 18:205-234.

Eberhard, W.G. 1995. The web and building behavior of Synotaxus ecuadorensis (Araneae, Synotaxidae). Journal of Arachnology 23:25-30.

Eberhard, W.G. 2007. Miniaturized orb-weaving spiders: behavioural precision is not limited by small size. Proceedings of the Royal Society of London B 274:2203-2209.

Eberhard, W.G. 2011. Are smaller animals behaviorally limited? Lack of clear constraints in miniature spiders. Animal Behaviour 81:813-823.

Eberhard, W.G. 2012. Cues guiding placement of the first loop of sticky spiral in orbs of Micrathena duodecimspinosa (Araneidae) and Leucauge mariana (Tetragnathidae). Bulletin of the British Arachnological Society 15:224-227.

Eberhard, W.G. 2013. The rare large prey hypothesis for orb web evolution: a critique. Journal of Arachnology 41:76-80.

Eberhard, W.G. 2014. A new view of orb webs: multiple trap designs in a single web. Biological Journal of the Linnean Society 111:437-449.

Eberhard, W.G. \& T. Hesselberg. 2012. Cues that spiders (Araneae: Araneidae, Tetragnathidae) use to build orbs: lapses in attention to one set of cues due to dissonance with others? Ethology 118:610-620.

Eberhard, W.G., I. Agnarsson \& H.W. Levi. 2008. Web forms and the phylogeny of theridiid spiders (Araneae: Theridiidae): chaos from order. Systematics and Biodiversity 6:415-475.

Edmunds, J. 1978. The web of Paraneus cyrtoscapus (Pocock, 1899) (Araneae: Araneidae) in Ghana. Bulletin of the British Arachnological Society 4:191-196.

Evans, H.E. 1966. The Comparative Ethology and Evolution of Sand Wasps. Harvard University Press, Cambridge, Massachusetts.

Fernández, R., G. Hormiga \& G. Giribet. 2014. Phylogenomic analysis of spiders reveals nonmonophyly of orb weavers. Current Biology 24:1772-1777.

Garb, J.E., T. DiMauro, V. Vo \& C.Y. Hayashi. 2006. Silk genes support the single origin of orb webs. Science 312:1762.

Griswold, C.E., J.A. Coddington, G. Hormiga \& N. Scharff. 1998 Phylogeny of the orb-web building spiders (Araneae, Orbiculariae: Deinopoidea, Araneoidea). Zoological Journal of the Linnean Society 123:1-99.

Hajer, J. 2000. The web of Trogloneta granulum Simon (Araneae, Mysmenidae). Bulletin of the British Arachnological Society 11:334-338.

Hajer, J. \& D. Řeháková. 2003. Spinning activity of the spider Trogloneta granulum (Araneae, Mysmenidae): web, cocoon, cocoon handling behaviour, draglines and attachment discs. Zoology 106:223-231.

Herberstein, M.E. \& A.M. Heiling. 1999. Asymmetry in spider orb webs: a result of physical restraints? Animal Behaviour 58:1241-1246. 
Herberstein, M.E. \& I.-M Tso. 2011. Spider webs: evolution, diversity and plasticity. Pp. 57-98. In Spider Behaviour, Flexibility and Versatility. (M.E. Herberstein, ed.). Cambridge University Press, Cambridge.

Hesselberg, T. 2010. Ontogenetic changes in web design in two orbweb spiders. Ethology 116:535-545.

Hesselberg, T. 2013. Web-building flexibility differs in two spatially constrained orb spiders. Journal of Insect Behavior 26:283-303.

Hingston, R.W.G. 1920. A Naturalist in Himalaya. Small, Maynard \& Co., London.

Kropf, C. 1990. Web construction and prey capture of Comaroma simonii Bertkau (Araneae). Acta Zoologica Fennica 190:229-233.

Kuntner, M., J.A. Coddington \& G. Hormiga. 2008. Phylogeny of extant nephilid orb-weaving spiders (Araneae, Nephilidae): testing morphological and ethological homologies. Cladistics 24:147-217.

LeGuelte, L. 1966. Structure de la toile de Zygiella x-notata $\mathrm{Cl}$. (Araignées, Argiopidae) et facteurs que régissent le comportement de l'araignée pendant la construction de la toile. Thése Publications de L'Universite de Nancy, Nancy.

Lopardo, L., G. Giribet \& G. Hormiga. 2010. Morphology to the rescue: molecular data and the signal of morphological characters in combined phylogenetic analyses - a case study from mysmenid spiders (Araneae, Mysmenidae), with comments on the evolution of web architecture. Cladistics 26:1-52.

Lubin, Y.D. 1986. Web building and prey capture in Uloboridae. Pp. 57-98. In Spiders: Webs, Behavior and Evolution. (W.A. Shear, ed.). Stanford Univeresity Press, Palo Alto, California.

Opell, B.D. \& H.S. Schwend. 2009. Adhesive efficiency of spider prey capture threads. Zoology 15:16-26.

Peters, H.M. 1939. Probleme des Kreuzspinnennetzes. Zeitschrift für Morphogie und. Oekologie der Tiere 36:179-266.

Peters, H.M. 1954. Estudios adicionales sobre la estructura de la red concéntrica de las arañas. Comunicaciones del Instituto Tropical de Investigacion y Ciencia 3:1-18.

Puniamoorthy, N., K.F.-Y. Su \& R. Meier. 2008. Bending for love: losses and gains of sexual dimorphisms are strictly correlated with the mounting positions of sepsid flies (Sepsidae: Diptera). B.M.C. Evolutionary Biology 8:155-166.

deQueiroz, A. \& P.H. Wimberger. 1993. The usefulness of behavior for phylogeny estimation: levels of homoplasy in behavoral and morphological characters. Evolution 47:46-60.
Roe, A. \& G.G. Simpson. 1958. Behavior and Evolution. Yale University Press, New Haven.

Ryan, M.J. 1996. Phylogenetics in behavior: some cautions and expectations. Pp. 1-21. In Phylogenies and the Comparative Method in Animal Behavior. (E.P. Martins, ed.). Oxford University Press, Oxford.

Scharff, N. \& J.A. Coddington. 1997. A phylogenetic analysis of the orb-weaving spider family Araneidae (Arachnida, Araneae). Zoological Journal of the Linnean Society 120:355-434.

Shear, W.A. 1986. Evolution of web-building in spiders: a third generation of hypotheses. Pp. 364 402. In Spiders: Webs, Behavior and Evolution. (W.A. Shear, ed.). Stanford Univeresity Press, Palo Alto, California.

Shinkai, A. \& E. Shinkai. 1988. Web structure of Conoculus lyugadinus Komatsu (Aranae: Anapidae). Acta Arachnologica 37:1-12. (in Japanese)

Simon, E. 1892. Histoire naturelle des araignées, Vol. 1. Librairie Encyclopedique de Roret, Paris.

Vollrath, F. 1986. Gravity as an orientation guide during webconstruction in the orb spider Araneus diadematus (Araneae, Araneidae). Journal of Comparative Physiology A 159:275-280.

Vollrath, F. 1987. Altered geometry of webs in spiders with regenerated legs. Nature 328:247-248.

Vollrath, F. 1992. Analysis and interpretation of orb spider exploration and web building behavior. Advances in the Study of Behaviour 21:147-199.

Wenzel, J. 1992. Behavioral homology and evolution. Annual Review of Ecology and Systematics 23:361-381.

Wiehle, H. 1931. Neue Beiträge zur Kenntnis des Fanggewebes der Spinnen aus den Familien Argiopidae, Uloboridae und Theridiidae. Zeitschrift für Morphologie und Ökologie der Tiere 23:349-400.

Witt, P.N. 1965. Do we live in the best of all possible worlds? Spider webs suggest an answer. Perspectives in Biology and Medicine 8:475-487.

Witt, P.N., C. Reed \& D.B. Peakall. 1968. A Spider's Web. Problems in Regulatory Biology. Springer. New York.

Zschokke, S. 1993. The influence of the auxiliary spiral on the capture spiral in Araneus diadematus Clerck (Araneidae). Bulletin of the British Arachnological Society 9:169-173.

Manuscript received 13 January 2014, revised 16 June 2015. 